\title{
Corrientes estéticas en torno a la ópera española (1868-1913)
}

\author{
Aesthetic Currents around Spanish Opera (1868-1913)
}

\author{
Francisco M. López Gómez \\ Universidad de Castilla-La Mancha \\ franmalogo@hotmail.com \\ ORCID iD: https://orcid.org/0000-0002-2988-2700
}

\section{RESUMEN}

El presente estudio partirá del análisis de las producciones operísticas españolas más relevantes compuestas entre 1868 (fecha en la que se comienzan a concebir las primeras óperas en castellano con el fin de fundar la ópera nacional) y 1913 (fecha del estreno de Tabaré de Bretón, última ópera creada por los compositores de la generación nacida a mediados de siglo, así como de La vida Breve de Falla), para así quedar adscritas a las tres corrientes estilísticas imperantes en España en esta época: la nacional o populista, la europea o cosmopolita y la esencialista. Ello permitirá ofrecer un panorama claro de las obras y tendencias estilísticas existentes en el género operístico español decimonónico, unas creaciones que servirían como antecedente y modelo a una nueva generación de compositores, liderados por Falla bajo una estética esencialista, que lograrán dar una difusión internacional a sus trabajos.

Palabras clave: Ópera española, ópera nacional, música del XIX, música del XX.

\begin{abstract}
Based on the analysis of the most important Spanish operas composed between 1868 (it is from this date that composers started to conceive the first works written in Spanish with the aim of founding a national opera) and 1913 (on this date it was premiered La vida Breve by Falla, together with Breton's Tabaré, the latest opera created by composers from the mid-century generation), the main aim of this paper is to associate these works to the three musical trends leading in the coetaneous Spain: the national or populist one, the European or cosmopolitan, and the nationalism of essences. This will allow us to offer a clear overview of the evolution of Spanish opera works created in the late Nineteenth Century. These works would serve as important precursors and models for a new generation of composers, led by Falla under an essentialist aesthetic, ideas that allowed them to give international dissemination to their work.
\end{abstract}




\section{CORRIENTES ESTÉTICAS EN TORNO A LA ÓPERA ESPAÑOLA (1868-1913)}

Key words: Spanish opera, National Opera in Spain, Nineteenth-Century Music, TwentiethCentury Music.

López Gómez, F. M. (2018). Corrientes estéticas en torno a la ópera española (1868-1913). Cuadernos de Investigación Musical, 2018, 6 (extraordinario), 256-292.

DOI: $10.18239 /$ invesmusic.v0i0.1947

\section{INTRODUCCIÓN: LA CUESTIÓN DE LA ÓPERA NACIONAL}

La ópera nacional constituyó, junto con la zarzuela, uno de los ejes vertebradores de la música española decimonónica, tanto en el terreno puramente teórico como en el compositivo (Casares, 1995: 92-94). Como tendremos ocasión de comprobar, se trató, en un principio, de géneros completamente opuestos: destinados a públicos de clases sociales distintas (si bien, a las funciones de zarzuela solía asistir también el espectador adinerado), concebidos bajo criterios literarios y musicales diferentes (lo cómico frente a lo serio; lo castizo, actual y popular frente a lo rancio y basado en las raíces históricas pasadas; lo fácil y alegre frente a lo dramático y lo elevado), y reflejo de ideales contrarios que enfrentaban los intereses del pueblo y sus tradiciones con los de la alta burguesía y la aristocracia, que luchaba por conservar su poder económico y político y legitimar su poder. En el terreno puramente estético, encontramos un claro paralelismo que presenta como antagonistas a los partidarios de crear el drama nacional a partir de la zarzuela (considerada por ellos el género nacional por antonomasia) y a los que pretenden conseguirlo imitando el lenguaje del género operístico cultivado por los compositores del resto de naciones europeas. Entre los primeros, que defendían un nacionalismo populista y pintoresco, encontramos ya desde la primera mitad de siglo a Masarnau y, desde el Sexenio Democrático, a críticos como Peña y Goñi o compositores como Barbieri y Arrieta. A los segundos, cuya propuesta pasaba por la apertura a Europa, quedan adscritos críticos como Soriano Fuertes y, posteriormente, Parada y Barreto. Estos planteamientos estéticos cristalizarían en dos tendencias, en principio antitéticas, a las que se adscribieron los compositores españoles que se dedicaron a la composición de óperas: la nacional o populista y la europeísta o cosmopolita. No obstante, como tendremos ocasión de comprobar más adelante, no se trata de planteamientos unívocos o aislados, lo que imposibilita en muchas ocasiones adscribir una determinada obra a una de las dos tendencias. Por otro lado, el fin último perseguido por los críticos, compositores e intelectuales del mundo musical hispano desde mediados de siglo, sería la fusión de ambas tendencias con el objetivo de europeizar o estilizar los cantos y bailes populares y encontrar la esencia de la música española, lo cual llevó al surgimiento de una nueva tendencia a finales de siglo: el nacionalismo de las esencias. 


\section{FrANCISCO M. LÓPEZ GóMEZ}

Junto a los problemas derivados de la búsqueda de esa nacionalidad idealizada, que se prolongarían hasta entrado el s. XX, nos encontramos con otros surgidos al procurar caracterizar el género que debía constituir la ópera nacional española. Ya a lo largo de la década de 1840, con motivo del surgimiento de la zarzuela renovada, existió en algunas ocasiones una confusión terminológica que quedó reflejada en la prensa, de manera que algunas óperas eran calificadas como zarzuelas y viceversa. Así sucedió, por ejemplo, con el estreno del primer acto de la ópera Padilla o el asedio de Medina de Espín y Guillén en el Teatro del Circo en 1845, calificada tanto en La Iberia como en la Revista de Teatros como zarzuela (esta última hasta un mes antes del estreno, "momento en que comenzará a denominarla como "ópera nacional"), mientras que en el libreto consta como "drama lírico” (Rodríguez, 2006: 80-81). Coincidiendo con la época de esplendor de la zarzuela, muchos la identificaron como la verdadera ópera española e, incluso, comenzaron a utilizar ambos términos indistintamente. Representativas a este respecto son las palabras de Arrieta, cuando clama en 1854 la protección del gobierno para el arte lírico nacional, utilizando los términos zarzuela y ópera española sin distinción alguna (Arrieta, 1853: 3). Con la completa revitalización y auge del género operístico en España a partir de la década de los 70, ahora completamente diferenciado del de la zarzuela, los términos quedaron totalmente disociados. El punto de inflexión, como bien señala Sobrino (2002: 86), sería el estreno de Don Fernando el Emplazado de Zubiaurre, una ópera en la línea de las producciones italianas y francesas compuestas a partir de mediados de siglo y que supuso una toma de conciencia para el resto de la década sobre el camino se debía seguir en la composición de ópera, diferenciada claramente del lenguaje de la zarzuela, en decadencia. Sin embargo, a partir de la década siguiente, principalmente de manos de Ruperto Chapí, la zarzuela experimentó una gran transformación, derivando en un género "híbrido y bifronte" con vuelos de ópera (Casares, 2012: 134), hasta tal punto que muchas obras (por citar algunas de este compositor, El milagro de la Virgen, La bruja, Curro Vargas, La cortijera) podrían considerarse como auténticas óperas cómicas. Teniendo esto en cuenta, los fines del presente estudio no incluyen el análisis de este tipo de producciones, al ceñirse al repertorio puramente operístico compuesto en esta etapa de auge del género en España que abarca medio siglo de producción desde el año 1868.

\section{ETAPA EMBRIONARIA (1868-1880): COSMOPOLITISMO}

El comienzo de la década de 1870 supuso para la historia de la ópera española un gran punto de inflexión, por cuanto significó la ruptura con el dominio estilístico y estético que venía ejerciendo hasta entonces la moda italiana sobre los trabajos operísticos de los compositores españoles. El pistoletazo de salida lo marcó el ya conocido concurso aparecido a finales de 1867 y destinado a premiar las mejores óperas en castellano y de nueva creación que se presentasen (Arrieta, Romero y Andía y Eslava, 1867: 262-263) ${ }^{1}$. A

\footnotetext{
${ }^{1}$ Convocado por Emilio Arrieta, Antonio Romero, Hilarión Eslava, Bonifacio Eslava, Monasterio, Saldoni, Remigio Calahorra y el tenor Aquiles di-Franco, su fin último sería formar un repertorio operístico nacional para que, tras ser aceptado por el público, sirviese como modelo para nuevas composiciones y diese lugar a un nuevo mercado lírico nacional paralelo al de la zarzuela.
} 


\section{CORRIENTES ESTÉTICAS EN TORNO A LA ÓPERA ESPAÑOLA (1868-1913)}

corto plazo, este acontecimiento supuso el estreno de dos de las óperas premiadas ${ }^{2}$, Don Fernando el Emplazado de Zubiaurre ${ }^{3}$ (la primera en ser puesta en escena en castellano, con la excepción de Marina de Arrieta -en realidad, una zarzuela transforma en ópera- $)^{4}$, y Una Venganza de los hermanos Manuel y Tomás Fernández Grajal ${ }^{5}$. Sin embargo, la verdadera importancia de este hecho residió en que posibilitó la salida a la palestra de una nueva generación de compositores decididos a triunfar en el género operístico (para desgracia de todos ellos, esto se convertiría en una lucha a contracorriente), lo que supuso el debut de los grandes autores de ópera en la España de finales del s. XIX, Chapí, Pedrell, Bretón y Serrano, así como el de otros como los hermanos Grajal, Barrera, Aceves, Llanos, Giró, Obiols, Nicolau, cuya carrera operística quedó pronto truncada.

Sin una escuela operística nacional precedente que pudiera servirles de modelo, sólo quedaba atenerse a una de las dos corrientes estéticas sobre las que únicamente se había especulado desde antes de mediado el siglo, la fundada en la tradición o la que apostaba por el progreso; en ese momento, no cabía conciliación alguna (Alonso, 1996: 167). Puesto que el haber desarrollado una ópera genuinamente nacional (tal y como era vista la ópera italiana, francesa y alemana) constituyó un indicador de desarrollo artístico a nivel internacional, la fundación de la ópera española pasó en estos inicios, paradójicamente, por la adopción de una estética internacional, símbolo del progreso. La regeneración nacional, que pretendía una revalorización de lo que se denominó 'cultura española', 'historia española', 'sentimiento español', etc. y la búsqueda de la España con honra, para la mayor parte de los compositores, no podía conseguirse mediante el uso de las melodías fáciles extraídas del mundo vulgar de la zarzuela, sino desde la adopción de un arte de altos vuelos destinado a las clases adineradas, que pudieran verse reflejadas en las glorias de la historia de la nación.

En suma, en sus inicios la labor de la fundación de una ópera nacional fue vista, desde el ideal regeneracionista, como una forma de engrandecer el arte musical español, lo cual pasaba por romper con la imagen de la España exótica y rica en folclore, de gran originalidad pero impregnada de un facilismo cuyo máximo vehículo de expresión se encontraba en la zarzuela y que derivaría, posteriormente, en las diversas manifestaciones

\footnotetext{
${ }^{2} \mathrm{El}$ primer premio fue compartido junto con la ópera de Zubiaurre por Atahualpa, ópera en cuatro actos de Enrique Barrera. Con respecto al segundo premio, fue otorgado a Una Venganza y a El puñal de misericordia (ópera en tres actos de Rafael Aceves y Antonio Llanos). El resto de las obras presentadas fueron El secreto de un monarca (ópera en cuatro actos, de autor desconocido), Luis Camoens (ópera en tres actos de Zubiaurre), Atala y Chactas (ópera en tres actos, también cuyo autor no se ha podido identificar) y El abencerraje (no es otra que L'ultimo abenzerraggio, de Pedrell). La relación de obras presentadas se conoce gracias al listado realizado por Jesús de Monasterio, que participó como miembro del tribunal. Ver: Archivo de la Real Academia de Bellas Artes de San Fernando, Leg. 335-1/5.

${ }^{3}$ Fue estrenada el 12 de mayo de 1871 en el recién fundado Teatro de la Alhambra de Madrid, a cargo de la orquesta asociada al Centro Artístico-Literario y con la iniciativa del empresario Aquiles di-Franco (uno de los convocantes del concurso que premió la ópera). Ver: "Centro Artístico-Literario: primera función de ópera española”, Diario Oficial de Avisos de Madrid: 12-05-1871, p. 4.

${ }^{4}$ La ópera de Arrieta fue estrenada el 16 de marzo de 1871 en el regio coliseo (apenas dos meses antes que Don Fernando el Emplazado), en una función a beneficio de Tamberlick.

5 Se estrenó el 31 de mayo de 1871 también en el Teatro de la Alhambra. Ver: "Teatro de la Alhambra: Centro artístico-literario", Diario Oficial de Avisos de Madrid: 31-05-1871, p. 4. Ver también el manuscrito del libreto: CEDOA-SGAE, MSS/14591/22.
} 


\section{FrANCISCO M. LÓPEZ GóMEZ}

del género por horas. El modelo lo constituía la ópera creada en Europa, pero alejada del modelo puramente italiano, que había regido la práctica totalidad de las obras del género creadas en España durante la primera mitad del siglo y que era percibido, del mismo modo, como símbolo de retraso y estancamiento cultural.

Como hemos ya mencionado, Don Fernando el Emplazado constituyó el primer punto de ruptura y referente para las óperas compuestas en España a lo largo de la década de los 70. Se trata de un drama desarrollado en un determinado momento de la historia de España, como la práctica totalidad de las óperas españolas, en el estilo operístico internacional franco-italiano que dominaba en Europa en la década de los años 60, que parte de la estructuración por secciones consolidadas con Rossini para modificarlas y adaptarlas a las exigencias del drama. Así, aunque toma el lenguaje vocal de compositores como Bellini y Donizetti, Zubiaurre hace uso de un estilo totalmente silábico; asimismo, consigue llegar a la concisión lírico-dramática operada por Verdi. De influencia francesa es el gusto por la forma romanza y la gran orquestación que, en estos casos, se restringe principalmente a los números finales, a los que imprime una monumentalidad conseguida por la presencia de múltiples grupos sociales diferenciados musicalmente dentro de la escena (representativo es el final del acto II, que entronca plenamente con la tradición de la grand opéra). No obstante, uno de los aspectos de la obra más valorados fue sin duda el uso de una sonoridad religiosa, heredada del lenguaje de Meyerbeer, que domina en las escenas de mayor tensión dramática y con la que caracteriza al personaje de D. Juan, el maestre de la Orden de Calatrava (uso del lenguaje organístico con un gran protagonismo de las voces graves, prolongadas progresiones cromáticas y profusión de acordes de séptima disminuida $)^{6}$.

La última ópera escrita por Zubiaurre, Ledia, que consiguió estrenar en el Real en 1877 (El Imparcial, 23-04-1877: 2), esta vez en castellano, le proporcionó mayor éxito aún que Don Fernando. Aunque el estilo musical y la forma en que está estructurada son muy cercanos a esta última, Ledia, ambientada en País Vasco en época de la Reconquista, renuncia a esa búsqueda de lo monumental que caracteriza a la grand opéra para centrarse en la complejidad interna de los personajes y en los conflictos que se originan como consecuencia de su interacción, en línea con las producciones italianas de los años 60-80 y con las óperas de Gounod y sus coetáneos. Esto no impide a Zubiaurre hacer uso de las técnicas que postergó Meyerbeer, como el simbolismo otorgado a la orquesta (en el caso de Ledia, éste se extiende al ámbito dramático, presente en momentos como la escena del sonambulismo y la bacanal desarrollada fuera de escena). El toque personal viene dado por la búsqueda de un pretendido misticismo medieval vasco tratado por Zubiaurre desde la óptica postromántica, un carácter expresado mediante la complejidad e indecisión armónica y que es especialmente visible en las escenas piadosas y religiosas, pero que se extiende a la totalidad de la ópera. Se trata de un recurso que encontramos ya en Don Fernando y que el compositor desarrolla, por tanto, plenamente en Ledia, completamente impregnada de este buscado ambiente místico del medievo vasco. Finalmente, destaca el color local conseguido

\footnotetext{
${ }^{6}$ Un análisis pormenorizado de la ópera puede consultarse en López (2016: 227-325).
} 


\section{CORRIENTES ESTÉTICAS EN TORNO A LA ÓPERA ESPAÑOLA (1868-1913)}

con la inclusión de un zorztiko y un bailable, así como de algunos momentos inspirados en la música popular vasca7.

La calurosa acogida que experimentó Don Fernando, calificada por algunos críticos de la época como la primera ópera nacional ${ }^{8}$, contrasta con la indiferencia con la que fue recibida la propuesta de los hermanos Grajal, Una Venganza, estrenada en el mismo Teatro de la Alhambra unos días después. Probablemente, el resultado se deba al estilo adoptado (tal y como opina Llorens, 2014: 198), condicionado por las obsoletas convenciones formales basadas en números cerrados adoptadas en las óperas compuestas desde Rossini a Bellini y Donizetti, con una clara diferenciación entre aria y recitativo, antandi y cabalette da capo y simétricas en los dúos, y una orquestación que primaba la voz -de marcado carácter vistuosístico- sobre el resto de instrumentos 9 . Idéntica recepción obtuvo la otra ópera compuesta, en este caso, por Tomás Fernández Grajal, El príncipe de Viana (1876, estrenada en 1885 en el Teatro Real; Diario Oficial de Avisos de Madrid, 10-02-1885), cuyo lenguaje armónico elaborado (modulaciones lejanas, cromatismos, séptimas sobre sensible y dominante cuya resolución queda siempre truncada) contrastaba fuertemente con la dependencia de una estructuración anclada en la Italia de mediados de siglo, con secciones estáticas, recitativos fríos y monótonos, y constantes cambios en el tiempo dramático de la representación ${ }^{10}$. Así, no es de extrañar que resultase lánguida y poco novedosa al público madrileño (El Día: 03-02-1885) y que no cumpliera las expectativas del "nivel más alto del genio y del arte musicales en nuestro país” (El Imparcial: 03-02-1885). El fracaso estrepitoso derivó, incluso, en una gran polémica en la que participaron, por un lado, Fernán Flórez y Peña y Goñi, defensores de la zarzuela (a la que consideraban la verdadera ópera nacional), y, por el otro, Tomás Bretón, indignado por las constantes e infundadas críticas sufridas por los compositores españoles en el terreno operístico ${ }^{11}$.

Siguiendo la senda abierta por Zubiaurre, la práctica totalidad de los compositores españoles que escribieron óperas durante el resto de la década de los 70 se aferraron a la corriente europeísta para servirse de las últimas tendencias lírico-dramáticas cultivadas en Francia e Italia. Otro de los compositores que presentaron uno de sus trabajos al concurso de 1867, Felipe Pedrell, siguió esta misma línea en la que constituyó su primera ópera, El abencerraje12, una obra en cuatro actos estructurada en números pero que busca la continuidad dramática. Su estilo conjugará las influencias de la grand opéra (abundancia de

\footnotetext{
${ }^{7}$ Idem. (2016: 326-395).

8 Así la calificaba Juan Casamitjana (1871: 4), quien, tras asistir al estreno, afirmaba: "He dicho la primera ópera nacional porque, si bien ya se ha representado la Marina zarzuela, transformada en ópera, tengo entendido [...] que la transformación no ha podido quitarle su primitivo carácter; al paso que D. Fernando el Emplazado tiene todas las condiciones que requiere el género al que pertenece: elevación de pensamiento; interesantes episodios, tanto armónicos como melódicos, especialmente en los ritornelo y enlaces de los periodos recitados; instrumentación nutrida; ritmo variado y, sobre todo, corrección esmerada". Citado por Sobrino (2002: 128).

${ }^{9}$ Para más información sobre la ópera y su estilo, consultar López (2016: 87-156).

${ }_{10}$ Un análisis de la obra y las circunstancias que rodearon su creación y recepción pueden consultarse en López (2016: 157-226).

${ }^{11}$ La polémica desatada puede seguirse en Bretón (1885: 2), Fernán Flórez (1885a: 2; y 1885b: 99) y Peña y Goñi (1885: 7). Una amplia reflexión y estudio sobre la misma puede encontrarse en Iberni (1995a).

${ }^{12}$ Fue estrenada en abril de 1874 en el Teatro del Liceo de Barcelona, tras ser traducida al italiano con el título de L'ultimo abenzerraggio.
} 


\section{FRANCISCO M. LÓPEZ GÓMEZ}

coros; escenas contrastantes que buscan el espectáculo visual; contraposición de fuerzas entre dos pueblos o religiones, con connotaciones políticas; tendencia a buscar temas exóticos; orquestación desarrollada que domina en ocasiones por encima de las voces; uso de una sonoridad religiosa, llena de misticismo (Cortès, 1995: 202-209), así como del órgano y de rezos fuera de escena), con las de la ópera italiana, presentes en la factura de los recitativos, de corte donizettiano, en las melodías a solo y en los coros "de estilo italiano puro" (Fargas y Soler, 1874: 3) e, incluso, en momentos que recuerdan los dúos rossinianos, aunque en un estilo vocal donde las fioriture están completamente ausentes (Cortès, 1995: 202-209). La crítica que realizó el crítico catalán José Pujol sobre la ópera subrayó, además, la caracterización psicológica diferenciada de cada uno de los personajes en los momentos corales ${ }^{13}$, una técnica que desarrolló Verdi en sus óperas de la década de los 50 (Budden, 1985: 551). Sin embargo, como procederán el resto de los compositores en esta etapa embrionaria de la ópera española, Pedrell hace uso también del folclore hispano (la sonoridad morisca está presente, por ejemplo, en el romance del Acto II), pero lo harán todos con el fin de dar una nota de color a la partitura, tal y como había realizado Verdi y los compositores franceses en muchas de sus óperas para dotarlas de carácter exótico. En definitiva, se trataba de complementar las corrientes cosmopolita y nacional, sin llegar nunca a una síntesis. Tal y como anotó el propio Pedrell en su partitura: "Para dar colorido a esta pieza y con la viveza propia del romance, el autor la ha compuesto sobre un tema que los árabes de Túnez han ejecutado hace poco en la Exposición de París, y sobre melodías que cree no son extrañas al carácter nacional”. De hecho, cuando el compositor revisa la partitura en 1889, en línea con su idea de nacionalismo musical basado en los cantos y bailes populares, es cuando va a introducir más elementos rítmicos y temáticos en deuda con el folclore hispano: el bolero "de carácter y tonalidad andaluza" (Obiols, 1874: 2) y la ronda del final del Acto I, la canción morisca del Acto II, y la zambra morisca "con ritmos profundos y notas ajenas a la tonalidad” (Obiols, 1874: 2) y la jerezana del Acto III.

El éxito experimentado por Pedrell con motivo del estreno de L'ultimo abenzerraggio lo animó a embarcarse en la composición de una nueva ópera, Quasimodo, estrenada en el Teatro del Liceo de Barcelona un año después que la primera (abril de 1875). Sin embargo, se trata de una obra que vuelve las miras nuevamente a la estética italiana, en un estilo similar a las primeras óperas compuestas por Verdi: acompañamiento que privilegia la voz sobre la orquesta, clara estructuración en números cerrados y división entre arias y recitativos, secciones repetidas, reexposiciones de las romanzas, giros melódicos italianizantes, etc. (Cortès, 1995: 216). A pesar de ello, no renuncia en algunos momentos a la inspiración francesa, como podemos observar en la canción de Esmeralda del primer acto, con un estilo vocal que recuerda al de Marguerite del Faust de Gounod, así como en muchos momentos del tercer acto, donde encontramos una orquestación más rica y exquisita, como la que acompaña la Revèrie de Esmeralda (Cortès, 1995: 217-218), de claro gusto meyerbeeriano.

\footnotetext{
13 "Pero cuando este [el compositor] se ve preciso a traducir en sonidos una situación en la que toman parte distintos personajes, y espresan [sic] estos diferentes sentimientos, de despecho unos, de odio otros, de esperanza estos, de desesperación los demás; y el conjunto es armónico, propio, sin desentonar en sus detalles, y produciendo el todo el efecto que describe y sintetiza el libreto [...]” (Pujol Fernández, 1874: 4).
} 


\section{CORRIENTES ESTÉTICAS EN TORNO A LA ÓPERA ESPAÑOLA (1868-1913)}

Muy distinta fue la última ópera concebida por el autor catalán a lo largo de esta década experimental dentro del panorama operístico español, Cleopatra, compuesta entre 1878 y 1879 bajo la influencia de su estancia en Francia. Se trata de una ópera de transición entre el estilo híbrido italo-francés de su primera obra y el lenguaje de Els Pirineus, donde existe la búsqueda de una mayor continuidad dramática (los cambios de escena se suceden sin interrupción), y donde el recitativo a la italiana se sustituye por el de estilo francés, de mayor riqueza melódica. Con respecto a la instrumentación, es mucho más evolucionada y selectiva, lo mismo que sucede en el terreno armónico, donde existen modulaciones constantes, uso del cromatismo -incluso en los temas- y sonoridades tanto orientales como modernistas (Cortès, 1995: 225-226). Este lenguaje, al que ha de sumársele el recurso a procedimientos wagnerianos como el recurso a la música histórica y el uso de leitmotivs (algunos de marcado cromatismo) asociados a ideas abstractas (Cortès, 1995: 227), sitúa a esta ópera en un lugar merecido junto a las producciones francesas contemporáneas, y al mismo nivel de creaciones autóctonas como Mitrídates de Serrano y Roger de Flor de Chapí, como veremos más adelante.

Otro de los compositores que inició su actividad como operista, y que dedicaría también una gran parte de sus esfuerzos creativos a dicho género, fue Tomás Bretón, quien en 1873 escribió su primera ópera, Guzmán el Bueno ${ }^{14}$, de pequeñas proporciones (en un acto) pero que, dada su calidad musical, sirvió al compositor para dar a conocer sus facultades compositivas y dramáticas. En este sentido, destaca la "profundización psicológica de corte verdiano" en la figura de Doña María, aunque también en la del protagonista principal, Guzmán, quien muestra tanto su lado fiero y orgulloso (siguiendo los ideales caballerescos medievales) como su parte más tierna, alejándose de una mera categorización psicológica según el rol que desempeñan. Como en L'ultimo abenzerraggio, en la ópera de Bretón destaca su pretendido carácter oriental, conseguido mediante el recurso al folclore nacional, del que extrae su lenguaje armónico, melódico y rítmico característico, para extrapolarlo originalmente a la orquesta, tal y como realiza, por ejemplo, en la canción de Fortun con la imitación de la técnica del rasgueo de la guitarra flamenca, asignada al arpa. Este lenguaje está enmarcado en el estilo vocal característico de la ópera italiana, que superpone al uso de una densa orquestación y que organiza a partir de una estructuración que supera las convenciones de la solita forma. Sin embargo, a diferencia de lo que desarrollarían los contemporáneos Chapí y Serrano (como veremos a continuación), Bretón no tuvo esa necesidad imperiosa de llevar al límite las relaciones tonales ${ }^{15}$. Así, incluso ya avanzada la década de los 80 y habiendo tenido ocasión de escuchar las profundamente a Wagner, se declaró refractario de sus principios, por su excesiva complejidad armónica y orquestal (Bretón, 1885: 24-25).

Respecto a Emilio Serrano, inició su andadura operística, a la que dedicó también gran parte de su carrera como compositor, en 1872, fecha en la que comenzó a concebir su

\footnotetext{
${ }^{14}$ Fue estrenada en noviembre de 1876 en el Teatro Apolo de Madrid.

15 Un análisis pormenorizado de la obra puede consultarse en López (2016: 513-550).
} 


\section{FRANCISCO M. LÓPEZ GÓMEZ}

primera ópera, Mitrídates ${ }^{16}$, la cual no finalizó hasta seis o siete años más tarde ${ }^{17}$. De esta obra destaca tanto su destacada instrumentación como su lenguaje armónico, completamente adaptados a la contemporaneidad operística francesa ${ }^{18}$, recursos que utiliza para caracterizar escenas de una gran complejidad emocional y en las que los acontecimientos se contraponen con las emociones de los personajes. La recurrencia no solo a un tema reminiscente, sino a una gran cantidad de ellos (hemos identificado, al menos, nueve), así como su transformación melódico-rítmica y armónica para crear distintos efectos dramáticos y sensaciones, es también un hecho remarcable en este sentido, y que constituirá, junto con los demás aspectos señalados, una característica común al resto de la producción operística de Serrano. Estos rasgos, unidos al uso de arias en un movimiento, secciones temáticas de gran concisión y un estilo vocal a medio camino entre el recitativo y el aria, sitúan a la obra dentro de los avances lírico-dramáticos desarrollados tanto en Francia por compositores como Gounod, Bizet, Flotow y Massenet, como en Italia por el Verdi maduro, una apreciación que no escapó a algunos críticos de la época (L., 1882: 3). Otro de los rasgos que debemos destacar de la ópera de Serrano es la recurrencia a la música popular hispana, la cual no cita o imita meramente, sino que le sirve de inspiración para crear un lenguaje totalmente original, tanto a nivel melódico-rítmico como armónico (como es la recurrencia al modo frigio), en lo que podría considerarse un primer acercamiento a esa buscada corriente del nacionalismo de las esencias, otro rasgo que será recurrente en la producción operística de Serrano, adelantándose en el terreno práctico a compositores como Pedrell. Aunque el uso de este lenguaje no se extrapola a toda la obra (sirve únicamente para caracterizar escenas concretas), la prensa elogió "la tendencia de que la música española, sin perder su carácter nacional, entre resuelta y valientemente en el camino de la música moderna y se coloque a la altura de los adelantos conquistados en todas las esferas del arte" ([Prensa no identificada $], 1882)^{19}$.

El último gran compositor de ópera en la España de 1870, y el más prolífico de la década, fue Ruperto Chapí, cuya vocación hacia este género es ya bien conocida (Iberni, 2009: 37-40). Su primer trabajo operístico, Las naves de Cortés ${ }^{20}$, fue fruto del primer concurso publicado por la recién fundada sección de música de la Real Academia de Bellas Artes de San Fernando en noviembre de 1873, el cual ganó por unanimidad y le valió una

\footnotetext{
16 SERrano, Emilio. Memorias autógrafas (capítulos referentes a sus años infantiles). Archivo de la RABASF, Signatura 6-82-1. La ópera no se estrenaría hasta el 14 de enero de 1882, en versión italiana en el Teatro Real. 17 Aunque no conocemos la fecha en que completó su obra, disponemos del registro de la propiedad intelectual correspondiente a la misma, donde se contempla que fue entregada al Ministerio de Fomento el 10 de enero de 1879. Ver: Registro de la Propiedad Intelectual no 2163, del 10-01-1879. Conservado en: Archivo de la RABASF, Signatura 6-82-1. No obstante, en la partitura para banda que se custodia en el Archivo del Real Conservatorio Superior de Música de Madrid (Signatura 3/1161) aparece anotada en la portada la fecha de 1878, en la que debió dar fin a la ópera: “A S.A.R. la Reina Sra. D”. Isabel de Borbón, princesa de Asturias. Mitrídates, ópera en tres actos. 1878".

18 Precisamente, tanto la riqueza de este lenguaje armónico como la rica instrumentación utilizada provocaría que, aún pasados cuatro años desde la fecha de su composición, fuera tachado a su autor de wagnerista, un calificativo que en el contexto madrileño siempre tuvo un matiz peyorativo hasta finales de siglo. Ver, a modo de ejemplo: El Imparcial, 15-01-1882: 3; L. (1882: 3); y Goizueta (1882: 3).

${ }_{19}$ Un análisis pormenorizado de la obra puede consultarse en: López (2016: 396-488); Fernández Álvarez (2016: 28-73).

${ }^{20}$ La ópera sería estrenada en castellano en el Teatro Real de Madrid, en abril de 1874.
} 


\section{CORRIENTES ESTÉTICAS EN TORNO A LA ÓPERA ESPAÑOLA (1868-1913)}

de las plazas como compositor pensionado a Roma (más tarde, se trasladará a Milán y París, lugares donde concebiría el resto de las óperas de esta primera etapa). Este primer trabajo, lejos de constituir un mero ejercicio de estudiante (como sí lo fueron el resto de trabajos presentados al concurso), es una obra que parte de la tradición italiana para subvertirla, utilizando las convenciones formales de mediados de siglo y dotando de una gran coherencia a cada uno de los números mediante el uso de pequeños motivos en la orquesta que se transforman y evolucionan como si del género sinfónico se tratase (será este un rasgo que caracterizará las cuatro óperas compuestas por el autor villenense en los años 70). Bajo la influencia de Bellini, Donizetti, Verdi, Meyerbeer, Gounod y Massenet, Chapí concibió una ópera llena de grandes contrastes, pero carente, por esto mismo, de una concepción dramática coherente. Las melodías que desembocan en un gran despliegue de lirismo (como la usada en el andante del tercer número) dan pronto lugar a episodios monumentales de naturaleza heroica, a la presencia de grandes marchas e himnos y del coro, que, lejos de ejercer una función decorativa, se introduce en la acción. En estos episodios el nutrido elemento orquestal cobra un gran protagonismo, adquiriendo una clara función dramática como nos lo presenta Meyerbeer. Finalmente, tal y como procedió Bretón con el número que inicia su pequeña ópera en un acto, Chapí introduce una escena musical de carácter pintoresco, determinado sin duda por el carácter del libreto de Arnao y como sucederá, inevitablemente, en su siguiente producción (también sobre libreto de dicho poeta $)^{21}$.

Durante su estancia en Roma, mientras estudiaba con interés las obras del repertorio instrumental del clasicismo vienés, puso música a La bija de Jeftê22, “drama lírico" en un acto. Se trata de una obra escrita en un estilo similar a la anterior, donde conjuga los diferentes estilos conocidos en el mundo operístico contemporáneo para adaptarlos a las variadas situaciones dramáticas. Sin embargo, encontramos ya una tendencia a desdibujar la línea melódica, asomando un estilo vocal que se convertirá en característico del compositor y que fluctúa entre el recitado y el arioso, lo cual consigue mediante el uso de modulaciones con una dialéctica emotiva. En general, se puede apreciar la influencia de la grand opéra en el gusto por imprimir un color local por medio de los elementos dramatúrgicos, musicales y coreográficos que intervienen en el ballet (destaca, en este sentido, el $\mathrm{n}^{\circ} 5$, un bailable donde predomina el uso de la escala tetratónica y una buscada sonoridad judía, con influencia de la música klezmer), así como con el uso de la pomposa andadura de marcha, la brutalidad ensordecedora de la orquesta o las armonías ricamente adornadas de Liszt y de Meyerbeer23.

Una vez finalizada La bija de Jefté Chapí se trasladó a Milán, donde esperaba mantener un contacto directo con las obras que ya conocía del Wagner anterior al Ring. Bajo su influjo, allí abordó, a lo largo de marzo de 1876, la composición de una nueva ópera en un

\footnotetext{
${ }^{21}$ Un análisis de la obra puede consultarse en López (2016: 551-593).

${ }^{22}$ Estrenada en el Teatro Real de Madrid en mayo de 1876, también en castellano.

23 Para un análisis completo de la obra, consultar: López (2016: 594-627).
} 


\section{FRANCISCO M. LÓPEZ GÓMEZ}

acto, La muerte de Garcilaso ${ }^{24}$. Aunque en ella sigue dominando la parte vocal frente al resto de la orquesta, destaca en muchos momentos la gran densidad de la escritura instrumental, que desempeña un papel importante a lo largo de la obra, hasta el punto de abarcar más de una cuarta parte de la duración total de la misma. La orquestación es también selectiva, adaptada a los sentimientos que desea transmitir. Por su parte, en los grandes números de conjunto, que sobresalen muchas veces por encima de las arias y los dúos, se percibe una influencia directa de Meyerbeer, Gounod e, incluso, de las primeras óperas importantes de Wagner. Por otro lado, las inquietudes sinfónicas de Chapí se reflejan en el cuidadoso trabajo motívico-temático que, como hemos señalado, es una seña de identidad que se percibe ya desde su primer trabajo operístico. En el terreno armónico destaca en la ópera el plan tonal, de forma que la recurrencia constante al contraste modal, ya presente en la obertura con la aparición del tema principal en los modos mayor y menor, permite condensar en una sola idea musical los dos pilares dramáticos de la ópera: la muerte y el honor ${ }^{25}$.

La madurez lírico-dramática demostrada por Chapí daría sus frutos en su última ópera de juventud, Roger de Flor s escrita durante su estancia en París entre marzo y julio de 1877 (Casado del Alisal, 1877)26. Así, en línea con sus producciones anteriores, hace uso de cada una de las técnicas de tradición tanto italiana como francesa y alemana para adaptarlas a cada una de las situaciones, dando lugar a un producto artístico no tan alejado de la tradición operística francesa, fundada en la ley del contraste escénico y musical. No es de extrañar que tanto los críticos partidarios de Wagner como los abiertamente antiwagnerianos resaltasen las bellezas que contiene la partitura de Chapí, con una gran "verdad en sus detalles" y adaptado en todo momento a las situaciones que requería el libreto (Esteban y Gómez, 1878: 381-382). En Roger de Flor encontramos las tendencias líricas más contemporáneas desarrolladas por Verdi, los procedimientos de los clásicos vieneses (en especial, Beethoven), el despliegue orquestal y coral de Meyerbeer, el gran trabajo de adaptación musical a la prosodia de Gounod, y el valor dramático y simbólico otorgado por Wagner a la orquesta. La densidad alcanzada en este último aspecto, con un importante papel dramático, junto con el trabajo motívico, llevan a Chapí al uso de un leitmotiv de tan solo siete notas de carácter descendente, que aparece en más de un centenar de ocasiones y que es sometido a procesos de variación (melódico-armónica y rítmica) para acompañar situaciones ligadas al acto de la conspiración y la traición, que constituyen el hilo dramático de la obra ${ }^{27}$. Tras esta última ópera, la carrera artística del compositor daría un giro rotundo, pues orientaría sus esfuerzos, partiendo de La Tempestad (1882), a la renovación de la zarzuela grande a partir del legado de los compositores anteriores dedicados a dicho género.

\footnotetext{
${ }^{24}$ No llegó a ser estrenada ante el público hasta su recuperación en el año 2009, cuando fue ofrecida en el Teatro de Esmirna de Turquía. No obstante, se realizó una audición privada de la misma en noviembre de 1876 en la Academia de Bellas Artes. Ver: Iberni (1995: 110).

25 Un análisis pormenorizado de la obra puede consultarse en López (2016: 628-676).

${ }^{26}$ Citado por Iberni (2009: 79). A finales de dicho mes de julio, Chapí ya había remitido su trabajo a España. Ver: Asmodeo (1877: 1).

${ }^{27} \mathrm{El}$ análisis de la obra puede consultarse en López (2016: 677-776).
} 


\section{CORRIENTES ESTÉTICAS EN TORNO A LA ÓPERA ESPAÑOLA (1868-1913)}

La corriente nacional se materializaría en la década de los 70 únicamente en una obra, ¡Tierra!, compuesta por Antonio Llanos en 187328 y que no estrenaría hasta 1879 en el Teatro de la Zarzuela de Madrid (junto con La Serenata de Chapí) (M., 1879: 3)29, lo cual es un hecho representativo. A pesar de tratar un asunto serio, que narra las dificultades e intento de rebelión durante la célebre travesía de Colón que finaliza en el descubrimiento de América, la ópera está escrita en el estilo musical propio de la zarzuela, con una gran influencia del folclore y la música popular hispana como medio para imprimir color local a la trama. Por tanto, esta sonoridad no queda asociada a situaciones concretas que puedan describir episodios pintorescos como sí que sucede en el resto de las óperas españolas coetáneas, sino que, a diferencia de estas, la ligereza y sencillez melódica domina en todo momento, sacrificándose con ello la veracidad dramática ${ }^{30}$. A pesar de ello, el éxito alcanzado fue mucho mayor si lo comparamos con el del resto de las óperas españolas de la década, hasta el punto de que fue, junto con Marina de Arrieta (zarzuela convertida en ópera), la única que se mantuvo en el repertorio de los teatros españoles en lo que restaba de siglo, un hecho esclarecedor de lo que el público demandaba de los compositores nacionales. La siguiente ópera compuesta por Llanos, Sagunto, estrenada en el Teatro Apolo en 1881, muestra presumiblemente el mismo estilo musical, que se percibe especialmente en los números de conjunto, de los cuales el compositor abusa en exceso (El Imparcial, 15/11/1881: 5).

\section{ETAPA INTERMEDIA (1880-1895): ECLECTICISMO}

La ópera Los amantes de Teruel de Bretón (compuesta en los primeros años de la década de los 80) inaugura una nueva fase en la ópera nacional española que se extenderá hasta 1895 y que protagonizará la creación y estreno de obras que muestran una mayor madurez compositiva en los autores que comenzaron su actividad en la década precedente. Se trata de una época donde conviven las técnicas utilizadas anteriormente con las novedades armónicas y dramáticas venidas de Europa, así como con una mayor presencia del folclore hispano, introducido junto al lenguaje internacional por unos compositores que adquieren plena confianza en sus facultades y en el potencial que para ellos adquiere el uso de recursos de procedencia hispana. El modo frigio, los grados rebajados, el juego modal, los floreos a base de tresillos, y las sonoridades moriscas darán paso, paulatinamente como veremos a continuación, a una sonoridad hispana estilizada, presente ya en las primeras óperas de Serrano y que desembocará, tras Els Pirineus de Pedrell, en la original aportación de Albéniz con su Pepita Jiménez.

Como la mayor parte de las óperas de esta etapa, Los amantes de Teruel es una obra ecléctica, en la que cada escena se presenta dotada de unos rasgos propios dependiendo de su carácter. Este es el motivo por el cual encontramos contrapuestos momentos

\footnotetext{
${ }^{28}$ En colaboración con Rafael Aceves, se trata del compositor de El puñal de misericordia, una de las óperas que mereció el segundo premio del concurso de 1867 y que, por desgracia, aún no ha sido localizada.

${ }^{29}$ Sobre el estreno La Serenata junto a la ópera iTierra!, consultar Casares (2012: 134).

30 Un análisis de la obra puede consultarse en López (2016: 489-512).
} 


\section{FRANCISCO M. LÓPEZ GÓMEZ}

convencionales como la cabaletta con que finaliza el pacto de los caballeros, de claro gusto donizettiano, con un estilo vocal que busca la línea declamada y un uso sinfónico y dramático de la orquesta teñida de un lenguaje tonal avanzado, a la que se le asigna un amplio entramado de motivos recurrentes a la manera de Wagner. En un término medio, ambos lenguajes desembocan, desde el punto de vista vocal, en las prácticas propias del Verdi de Aida y, desde el dramático, en la ley del contraste que rige las escenas de la grand opéra francesa (Sánchez, 2002: 145-146). Bajo el influjo de esta última está diseñado, claramente, el dúo alrededor del cual se desarrolla el tercer acto de la ópera ${ }^{31}$, dando lugar a momentos de gran inspiración (destaca la romanza de Isabel del $n^{\circ} 12$ ) que se contraponen a otros de marcada tensión (como el preludio que inicia el Acto III). En la misma línea ecléctica, Bretón hace uso en diversos momentos (como había ya realizado en Gurmán el Bueno) del color local mediante sonoridades andalucistas y melodías sencillas inspiradas en el folclore hispano, pero se restringe a momentos puntuales, como sucedía con las óperas hispanas de la década anterior.

La siguiente ópera compuesta por Bretón fue Garín o L'eremita di Montserrat, escrita en 1891 y estrenada al año siguiente en el Teatro del Liceo. Si bien presenta muchos rasgos en común con la anterior, en esta obra el compositor, con el fin de ambientar la obra en el contexto geográfico en que se desarrolla, comienza a introducir de forma más segura y explícita el folclore hispano, en este caso de origen catalán: una reelaboración de la canción popular La cativa (balada de Witilda del Acto I), una cita prácticamente literal que supone una orquestación colorística de los temas populares La Filla del Marxant, Lo cant dels aucells y Lo Nostramo, y una ampurdanesa y una sardana creadas ex novo (todo ello en el último acto) (Sánchez, 2002: 190-192), una presencia del elemento popular regional que determinó el gran éxito de la ópera tras su estreno en Barcelona. No obstante, y a pesar de sucederse las escenas sin solución de continuidad, el plan dramático sigue obedeciendo a la búsqueda del contraste entre las distintas situaciones que se plantean (Mitjana, s.d.: 103) ${ }^{32}$, y en determinados momentos (en especial en los encuentros amorosos) el estilo predominante sigue siendo el italiano. Si el entramado de motivos reminiscentes en Los amantes era denso, en Garín existe un acercamiento aún mayor al concepto wagneriano, de manera que a cada personaje le es asignado un leitmotiv característico $^{33}$, del que se apropiará la orquesta con un lenguaje armónico tonal avanzado para sustentar un discurso vocal en muchos momentos cercano a la declamación. Sin embargo, este lenguaje es más cercano al Wagner romántico de Tannbäuser (es inevitable pensar, incluso, en momentos concretos como el racconto de la peregrinación a Roma, que guarda muchas similitudes con el de Garín del último acto)

\footnotetext{
31 Algunos críticos no pudieron evitar establecer paralelismos con el célebre dúo del Acto IV de Les Huguenots, si bien el lenguaje de Bretón está plenamente ligado a la contemporaneidad en cuanto a procedimientos musicales se refiere.

32 Citado por Sánchez (2002: 188).

33 “Cromático para una Witilda absorta en su amor, amplio y majestuoso para Wifredo, más melancólico para Aldo, una cuarta disminuida descendente para el vengativo Teudo y un solemne coral para las alabanzas del coro a la montaña sagrada" (Sánchez, 2002: 190).
} 
(Mitjana, s.d.: 112) ${ }^{34}$, Der Fliegende Holländer y Lohengrin que al drama lírico ofrecido en el Ring.

Las duras palabras pronunciadas por Pedrell tras el estreno de la obra, criticando el uso del "canto vulgar y ramplón transportado a la escena, como quien dice, por traslado de dominio” (Pedrell, c. 1911: 320-321)35 y defendiendo, por tanto, la vía esencialista, no impidieron que Bretón diera un paso si cabe más vasto hacia la idea de construir la ópera española mediante el uso (ya fuera literal o inventado) de la música popular. Para el compositor salmantino, ello suponía renunciar, al menos en parte, al complicado lenguaje armónico wagneriano y adoptar el utilizado por los compositores italianos que habían iniciado la corriente verista. La Dolores, la ópera de más éxito de Bretón, compuesta en 1894 y estrenada al año siguiente en el Teatro de la Zarzuela (un hecho representativo y buscado, con gran acierto, por el compositor), le permitirá utilizar de manera verosímil el lenguaje cómico del sainete al estar fundada en el drama rural de Feliú y Codina, inspirado en hecho reales acaecidos en Calatayud en la primera mitad de siglo. La partitura, plagada de melodías inspiradas en la música popular hispana, como la famosa jota de la ópera, pasacalles, pasodobles, etc., es fruto también de la inspiración que encontró Bretón tras visitar esta región aragonesa (Sánchez, 1998). Asimismo, tal y como habían procedido los compositores de zarzuelas desde mediados de siglo, Bretón hace uso del estilo característico de la ópera cómica italiana de los años 30-40, pero se trata de momentos que pronto ceden paso a un lenguaje más contemporáneo -siempre de tradición italiana- que, como apreciaron algunos críticos, presenta similitudes con Cavalleria rusticana (Esperanza y Sola, 1895) ${ }^{36}$. Sin embargo, la principal aportación del compositor con esta obra la encontramos en el uso de un lenguaje típico hispano -cadencias andaluzas, segundas aumentadas, ambigüedad modal- que aparece en algunos momentos "camuflado entre la trama compositiva” (Sánchez, 2002: 240), lo cual lo acerca por vez primera a la corriente esencialista. Destaca en este último sentido el momento del desenlace, donde aparecen algunas cadencias andaluzas mezcladas entre el complejo discurso armónico de gran inestabilidad tonal.

Antes de que tuviera lugar el estreno de los Amantes, Emilio Serrano se embarcaría también en la composición de su segunda ópera, Juana la Loca (en cuatro actos), concebida entre 1885 y 1888 y estrenada en el Teatro Real un año más tarde que la obra de Bretón. Sin embargo, aunque presentan algunos rasgos comunes, como es el influjo de la ópera francesa contemporánea y del estilo del Wagner romántico, Serrano se adelanta al resto de compositores españoles coetáneos desarrollando con una gran madurez lo que ya había concebido tímidamente en Mitrídates: el uso en determinados momentos de un lenguaje musical que busca la esencia del folclore hispano, de forma que sus rasgos diferenciadores quedan inmersos en el discurso musical. Con ello, consigue imprimir a la ópera un color local que se traduce en el uso del modo frigio, la cadencia andaluza, giros modales característicos, el tresillo como adorno rítmico-melódico, temas de carácter popular

\footnotetext{
34 Citado por Sánchez (2002: 194).

35 Citado por Sánchez (2002: 194).

36 Citado por Sánchez (2002: 238).
} 


\section{FRANCISCO M. LÓPEZ GÓMEZ}

enriquecidos armónicamente, etc. Asimismo, la utilización de motivos y temas recurrentes se hace extensiva a toda la obra, de forma que los encontramos asociados a numerosas situaciones y personajes y transformados ingeniosamente para dar lugar a su propio discurso dramático, subrayando los acontecimientos o adquiriendo una entidad propia ${ }^{37}$. Sin embargo, su uso sistemático, así como la sonoridad eminentemente cromática que domina la obra, no lo convierte en wagneriano, pues para Serrano "la forma sinfónica, como el discurso literario, pierde su fuerza cuando se la utiliza sistemáticamente en un dúo amoroso, en un acto entero e incluso a través de toda una producción escénica" (Serrano, Memorias) ${ }^{38}$. Para este tipo de situaciones, por tanto, el compositor español recurre, en ocasiones, a la tradición italiana ${ }^{39}$ y a la de franceses como Gounod, Massenet, Saint-Saëns y Berlioz ${ }^{40}$. Se trata, en definitiva, de una ópera de gran valor artístico entre las producciones españolas de finales de siglo en la línea que dominaba el panorama estético hispano: el hibridismo estilístico que buscaba una plena adaptación a cada una de las situaciones planteadas por el libreto.

El mismo año en que Serrano ve estrenada su Juana la Loca, se embarca en la composición de su siguiente ópera, Irene de Otranto ${ }^{41}$. Debido a las acusaciones de wagneriano que le valió su anterior obra, siempre en un tono despectivo, el compositor, tal y como él mismo expresó, torció el camino seguido hasta entonces (Serrano, Memorias) ${ }^{42}$, retrotrayéndose a la tradición francesa anterior de Meyerbeer y Gounod y a la italiana de Donizetti y el Verdi de los años $50^{43}$, sin renunciar en algunos momentos, no obstante, al avanzado lenguaje armónico que le caracteriza. Así, el lirismo, con melodías de amplio vuelo en lugar de las tendentes al declamado, es en muchos momentos dominante, como

\footnotetext{
${ }^{37}$ El uso de dichos temas y motivos aparece analizado en Fernández Álvarez (2016: 100-149).

38 Citado por Fernández Álvarez (2016: 100).

${ }^{39}$ De carácter italiano es, sin duda, la frase principal del racconto con que hace entrada en escena el capitán Don Alvar, uno de los principales temas recurrentes de la ópera (Fernández Álvarez, 2016: 109). En concreto, algunos momentos de la ópera recuerdan al Don Carlos (el caso, por ejemplo, de la cabaletta del dúo inicial del Almirante y D. Alvar) y a la Forza del destino verdianos (como el coro que da inicio al Acto II, similar al que introduce el mismo acto de la ópera de Verdi).

40 Destaca, en este sentido, el lamento de la reina del final del Acto II al conocer la traición de Fernando ('Rencor y penas en mi inculcaste'), original y de gran inspiración y que servirá de base al gran concertante policoral que cierra dicho acto. De tradición francesa es también la romanza de D. Alvar de la Escena IV del Acto III, construida a partir de un contorno melódico predominantemente lineal sobre un sustento armónico caprichoso y complicado. La tradición de la grand opéra se deja ver, asimismo, en el inicio del Acto III, que muestra en la plaza de la catedral de Burgos un cuadro escénico monumental con participación del pueblo, las órdenes religiosas, los nobles y los guardas del reino; sin embargo, en un momento como este domina el folclore hispano, que actúa como marco de esta escena y da lugar a cuatro bailables de clara inspiración popular, al modo del ballet obligado del género operístico francés.

${ }_{41}$ Fue estrenada también en el Teatro Real en febrero de 1891, si bien esta vez obtuvo el beneplácito de hacerlo en castellano, por vez primera.

42 Citado por Fernández Álvarez (2016: 165).

43 Significativo es el tema con el que construye el dúo de amor que inicia el primer acto, así como la romanza de Irene del Cuadro III (Acto II) y el dúo apasionado que le sucede entre ella y Roberto, alcanzando todos estos momentos un caluroso recibimiento por la crítica y el público. La tradición francesa se deja sentir en escenas como la gran tempestad que da fin al acto intermedio; la que inicia el último acto, con un coro de guerreros, mercaderes y el pueblo que evitan que entren a la ciudad Guillermo y Roberto, a los que sigue una marcha religiosa protagonizada por el órgano que invita a los fieles a entrar en la iglesia mientras los soldados procuran impedir que la peste se propague; y el espectacular cuadro descriptivo final, que protagoniza la quema de la iglesia con Guillermo en el interior, seguido de los dos amantes.
} 


\section{CORRIENTES ESTÉTICAS EN TORNO A LA ÓPERA ESPAÑOLA (1868-1913)}

también lo son los números corales; y la orquesta, en la que destaca la cuerda, cede un mayor protagonismo a las partes vocales. Asimismo, hace uso de temas y motivos reminiscentes, pero sin el calado que regía su anterior obra, ni tan siquiera con la profundidad con que aparecen ya en Mitrídates. En la misma línea, el recurso a la tradición musical hispana no sucede con miras a su fusión con la tradición musical europea, sino que existe una cita y reelaboración mucho más directa, como las melodías populares del coro que inicia el Acto II, todo ello con el fin de acercarse a los gustos del público del Real, quienes esperaban de la ópera española un producto cercano en estilo a la zarzuela. El resultado fue una obra que no ofrece la originalidad y verosimilitud del drama moderno pero que tampoco consigue momentos de destacada "frescura" e "inspiración" (Esperanza y Sola, 1891: 115) ${ }^{44}$, por quedar la melodía truncada con el artificio armónico.

Junto a la actividad operística de los compositores mencionados que comenzaron su andadura en la década de los 70, destaca también el catalán Antoni Nicolau, algo más joven que Chapí, Bretón y Serrano. Debido a la falta de estudios actuales sobre sus óperas, resulta complicado encasillarlas, más aún partiendo de la crítica española contemporánea condicionada por los juicios enfrentados orientados a la exaltación o degradación de lo que tendía a lo wagneriano o a lo franco-italiano. Sobre su primera ópera, Constanza, estrenada en el Teatro Principal de Barcelona en 1878, no nos han llegado datos que nos revelen sus principales rasgos. Sin embargo, cuatro años más tarde, a raíz del estreno en París de su poema sinfónico para coro y orquesta, sabemos que su lenguaje se caracterizaba por la "delicadeza de expresión, una propiedad en los efectos y un conocimiento tan exacto de la orquesta, que le colocan desde luego en primera fila entre los jóvenes maestros más notables de la escuela moderna" (Arnedo, 1887: 1). Estos rasgos pueden observarse en su segunda ópera, Un rapto, estrenada en el Circo de Price de Madrid en marzo de 1887. A pesar de anunciarse como zarzuela (La Dinastía, 08-03-1887: 3), opereta cómica (E. F., 1887: 2) u ópera cómica española (Arnedo, 1887: 1), se trata de una ópera seria en la línea de Irene de Otranto (teniendo presente el hecho de que se produjo varios años antes), por cuanto se atiene al principio de la variedad y la ley del contraste presentes en la grand opéra meyerbeeriana para contraponer momentos que beben de la tradición de la zarzuela y el lenguaje cómico italo-francés, con otros de una grandiosidad buscada a través de una instrumentación plena y manejada con "gran facilidad y maestría" (El País, 06/03/1887: $3)^{45}$, como es en este último caso el final del acto intermedio, "un número descriptivo de primer orden" (Arnedo, 1887: 2). Nicolau hace también uso de temas y motivos reminiscentes (destacan el "motivo de los caballeros" y el "motivo del rapto") (Arnedo, 1887: 2), si bien las críticas de prensa no permiten comprender la presencia y alcance de

\footnotetext{
${ }^{44}$ Citado por Fernández Álvarez (2016: 187).

45 De corte meyerbeeriano es, por ejemplo, el final del Acto I, en el que se encontraron paralelismos con "el concertante" de Les Huguenots (El Pabellón Nacional, 08-03-1887: 3). También de influencia francesa es el dúo entre Gontran y Roberto del primer acto, que "ofrece algunos giros y cadencias a lo Gounod” (E. F., 1887: 2); el preludio instrumental con carácter de nocturno que describe la salida de la reina de la noche (también recuerda a Gounod); el dúo entre Gontran y Diana del final del Acto II, que "contiene alguna reminiscencia del $4^{\circ}$ acto del Fausto" (E. F., 1887: 2); así como los couplets que canta el conde de Beaumont, donde "la orquesta tiene unos efectos y unas armonías que pintan admirablemente el carácter báquico de la canción" (Arnedo, 1887: 1-2).
} 


\section{FRANCISCO M. LÓPEZ GÓMEZ}

estos. No obstante, en muchos puntos, como la romanza de soprano, el dúo de soprano y barítono, el brindis coreado, la serenata de barítono, el segundo acto en general y el concertante final, sobresale el aspecto melódico, momentos que decidieron el triunfo del autor (La Dinastía, 08-03-1887: 3). Respecto a su última ópera, Corazón de fuego (compuesta alrededor de 1895) (J. H. P., 1895: 3), calificada de "zarzuela dramática" (J. H. P., 1895: 3), deducimos que es similar en estilo a la anterior, con "unos bailables y un concertante de grandioso efecto; [...] factura orquestal de primer orden, los temas inspirados y descriptivos" (J. H. P., 1895: 3).

Respecto a Felipe Pedrell, en esta etapa intermedia se volcó en la composición de la que será su obra más ambiciosa, Els Pirimeus, compuesta entre 1890 y 1891 y estrenada en italiano a comienzos del siguiente año en el Teatro del Liceo. Como los otros dos grandes trabajos hispanos de la década anterior, Los amantes de Teruel de Bretón y Juana la Loca de Serrano, el influjo de Wagner en el uso sistemático de temas y motivos recurrentes es determinante en el planteamiento dramático y orquestal, hasta el punto de que Pedrell se planteó acompañar la representación con una guía de temas y otros elementos (Cortès y Colomer, 2004: XIII). No obstante, a diferencia de estos la línea vocal y su exquisito acompañamiento en la orquesta beben del lied romántico y no de la tradición francesa, con especial predilección por los lenguajes de Schubert y Liszt, un lenguaje que Pedrell desarrolló ya desde 1879 con sus Lais (Bonastre, 2002: 193-194; Zabala, 2004: 325-334). Por otro lado, bajo el prisma del nacionalismo el compositor catalán hace uso no sólo del folclore nacional, sino también de la música histórica para imprimir un color local a su obra (destaca el Aleluya del prólogo ${ }^{46}$ y géneros como la tençó, el lai y el sirventès). A pesar de ello, se trata, ante todo, como subrayan Cortès y Colomer (2004: XIV), de una ópera que busca en todo momento la monumentalidad de la grand opéra y que utiliza su orquestación, planteamiento dramático ${ }^{47}$ y tratamiento vocal ${ }^{48}$, de manera que encontramos influencia de las óperas francesas de Meyerbeer, Berlioz, Thomas y Verdi, y de la etapa romántica de Wagner ${ }^{49}$. De carácter eminentemente francés es también el gusto por los bailables y lo exótico, ligado en este caso especialmente al personaje del Raig de Lluna y al coro de almogávares, donde el lenguaje armónico orientalizante (segundas aumentadas, cromatismo, juego modal) se funde con el folclore catalán (recurso que había explotado ya Chapí en su Roger de Flor). Con relación al uso del folclore hispano, Pedrell puso en práctica los ya conocidos presupuestos volcados, mientras componía su ópera, en su opúsculo Por nuestra música. Así, los cantos populares son reinventados a partir del uso de lo que él consideraba sus rasgos diferenciadores armónicos, melódicos y rítmicos. Como hemos

\footnotetext{
46 "Basado en una paráfrasis de una Lamentación a once voces y del salmo Cum invocarem a quince partes de Juan Bautista Comes" (Cortès y Colomer, 2004: XV).

${ }_{47}$ Muchos lugares en la ópera presentan la variada y contrastante estructuración formal que encontramos en el aria 'Bénédiction des poignards' de Les Huguenots o en la romanza de Wolfram 'O! du mein holder Abendstern' de Tannhäuser (Cortès y Colomer, 2004: XV).

48 Destaca el uso grandioso de lo policoral, que da lugar a la presencia de distintos estratos sociales en la escena, como podemos observar en el concertante del prólogo, que reúne a caballeros, damas de Foix y pueblo (formado por niños y resto del coro).

49 Similar proceso armónico al de la marcha de los peregrinos de Tannhäuser encontramos en el tema de la "corte de amor" (Cortès, 1991-2: 81).
} 


\section{CORRIENTES ESTÉTICAS EN TORNO A LA ÓPERA ESPAÑOLA (1868-1913)}

comprobado con la obra de Serrano, no se trata de un procedimiento nuevo, pero, a diferencia de éste, sí ejercería una influencia directa en compositores de la generación posterior como Falla (Cortès y Colomer, 2004: XV).

Al final de la etapa que nos ocupa (1880-1895) hizo aparición sobre la escena española otro compositor también catalán de la misma generación que Chapí, Bretón, Serrano y Nicolau, Manuel Giró, quien a comienzos de la década de los 70 ya había concebido una ópera cómica, El gran cacique de la aldea, que, a juzgar por su nula mención en prensa, no llegó a estrenarse. De sus restantes siete óperas ${ }^{50}$, tenemos noticia casi exclusivamente de El sombrero de tres picos (firmada como 'comedia musical en tres actos') (Eme., 1893b: 1), compuesta en París en 1892 (La Dinastía, 10-11-1891: 3) y estrenada en mayo del año siguiente en el Teatro del Príncipe Alfonso de Madrid. Su larga estancia en Francia (permaneció allí a lo largo de dieciocho años) (Eme., 1893a: 1) determinó su estilo, que parte del lenguaje de Meyerbeer y Gounod e imita el de los compositores franceses de ópera de finales del s. XIX, con el uso de un lenguaje armónico tonal avanzado que sustenta por lo general una línea vocal declamada ${ }^{51}$. La ópera que nos ocupa es una obra estructurada en números y en la que existe una clara diferenciación de arias, romanzas, dúos, coros, etc. (La Dinastía, 03-11-1893: 2). Asimismo, como las de Bretón y Serrano y como las sinfonías y obras religiosas del propio Giró, está impregnada del "aroma y sabor peculiares de nuestra raza" (Eme., 1893a: 1), un aroma que consigue muchas veces con la cita directa o reelaborada (en especial en los bailables, de "extraordinaria belleza y mérito") (Eme., 1893a: 1), pero otras lo hace con el estudio de los rasgos diferenciadores del folclore hispano, que presenta perfectamente insertos en la tradición europea ${ }^{52}$. A pesar de las críticas recibidas con motivo de la óptica con que fue abordada la obra de Pedro Antonio de Alarcón, en su siguiente ópera, Nuestra Señora de París ("melodrama lírico" compuesto en 1894 y estrenado en el Teatro Novedades de Barcelona tres años más tarde), sigue la misma senda, si bien algunos críticos encuentran también similitudes en muchos momentos con "una aplaudidísima obra" de Wagner a nivel orquestal y sonoro, como en el dúo de soprano y tenor del segundo acto (J. H. P., 1897: 1), con lo cual podemos presuponer un influjo de las óperas románticas del compositor alemán anteriores al Ring. Finalmente, en su ópera Carlos $V$, compuesta alrededor de 1893 pero que no llegó a estrenarse ${ }^{53}$, se decanta

\footnotetext{
${ }^{50}$ Las no mencionadas en el cuerpo del texto son: Il Rinnegato Alonso García, ópera en cuatro actos compuesta en 1884, estrenada en junio del año siguiente en el Teatro del Liceo; Florinda, en tres actos, presumiblemente posterior a Carlos V; Ermantho o Hermonth, ópera en tres actos compuesta en 1895 y que quedaría igualmente sin estrenar; y El estudiante de Salamanca / L'Étudiant de Salamanque, de la cual no poseemos más datos.

${ }^{51}$ Ello determinó el fracaso de la ópera tras su estreno en Madrid, al estar basada en un libreto que ofrecía numerosas ocasiones para lo cómico y ligero, pero musicalizada solemne y grandiosamente, "como si [el compositor] no pudiera sustraerse de su temperamento, más dado a las composiciones sinfónicas y religiosas que a la música flexible -passer le mot- ligera y chispeante" (Eme., 1893b: 1).

52 “[...] ese estudio profundo que ha hecho de esta particular manifestación del arte, donde predomina lo espontáneo y lo patriótico, lo sencillo y lo sentimental, el señor Giró, con su potente talento artístico lo reviste y modifica, y lo que antes era sola expresión de la musa popular, lo vemos bajo la moderna y filosófica escuela, ya dominando los modelados contornos del poético y fantástico Meyerbeer, ya recorriendo con su soñadora imaginación los dilatados horizontes que atesora y eterniza la ciencia armónica de Wagner" (La Dinastía, 03-11-1893: 2).

53 Según las noticias de prensa, Giró presentó su obra a la empresa del Teatro Real para que fuera juzgada (de ello se encargaría una comisión compuesta por Chapí, Zubiaurre y Bretón) con vistas al estreno en 1894, pero
} 


\section{FRANCISCO M. LÓPEZ GÓMEZ}

por el uso de un lenguaje internacional -tendente al melodismo italiano que se volvía a imponer en la escena europea con el movimiento verista-, en detrimento de la sonoridad hispana:

Dicha ópera tiene el sello característico de las obras maestras, $[\ldots]$ tiene ese sabor clásico, excesivamente original de la verdadera obra del arte; la melodía, a la par que artísticamente bella, es un contorno acabado, lleno de valentía y majestuosidad y los periodos armoniosos que sucesivamente se desarrollan en él, reflejan de un modo evidente con todos sus primores y riquezas, la intuición artística y el portentoso talento del genio (La Dinastía, 03-11-1893: 2).

\section{ETAPA MADURA (1895-1915): NACIONALISMOS DE LAS ESENCIAS}

Mientras tanto, fuera de nuestras fronteras, Isaac Albéniz intentaba probar suerte como compositor también en el terreno de la música escénica. El estreno venturoso en Londres de su opereta The Magic Opal, una obra que presenta varios números impregnados del folclore andaluz (ambigüedad modal, floreos, ritmos sincopados, sonidos inspirados en el flamenco, etc.) (Clark, 2002: 111), lo animó a empezar la composición ese mismo año, bajo la protección de Coutts, de la "ópera romántica" Henry Clifford (en lengua inglesa, aunque traducida al italiano para su estreno en el Liceo de Barcelona en 1895). Su estancia inmediata en París le sirvió para conocer algunas obras de Debussy (entre ellas, el Prélude à l'Après-midi d'un faune y la ópera Pelléas et Mélisande), así como a Satie, Séverac y otros compositores franceses (Clark, 2002: 136). No obstante, se trata de una obra que sigue la tradición de la grand opéra ${ }_{s}$ con escenas contrastantes, una gran orquestación y el gusto por las criaturas e historias fantásticas (destacan los cantos de hadas, danzas de gnomos y nereidas del segundo acto) y por lo religioso ${ }^{54}$. Además, el peso de la tradición vocal italiana, heredada de Verdi y renovada por los primeros veristas ${ }^{55}$, sigue presente, lo cual puede observarse en la primacía que concede en muchos momentos a la voz sobre la orquesta y en el "carácter directo y emocional de la música" (Clark, 2002: 151-152). También como el resto de los compositores españoles contemporáneos, hace uso de diferentes temas y motivos reminiscentes y de un lenguaje armónico con una gran profusión de cromatismos que se extienden algunas veces a los momentos de mayor lirismo (Clark, 2002: 155). A pesar de ello, Albéniz sigue sin renunciar a sus raíces andaluzas, y lo hace con su idea esencialista en línea con el pensamiento de Pedrell, de

ello nunca tuvo lugar, a pesar de que su representación inminente se llegó a anunciar en prensa (La Dinastía, 03-11-1893: 1; El País, 07-10-1894: 1).

${ }^{54}$ En este sentido, cabe subrayar el canto fúnebre del comienzo del primer acto, "hermosa página en que no se sabe qué admirar más, si la sabia manera de combinar las voces de hombres y mujeres, o la amplitud y belleza de las ideas musicales, directamente bebidas en las fuentes purísimas del canto llano". "Noticias de espectáculos: la ópera de Albéniz" (El Día, 10-05-1895: 4).

55 De un claro ambiente verista es el inicio de la obra, con el carillón que acompaña el coro de mujeres, hombres y monaguillos, así como con el coro de niños que cantan alegremente mientras se escuchan las campanas “tocando a fiesta”. Ver: La Iberia, 10-05-1895: 2; La Iberia, 14-05-1895: 2. 


\section{CORRIENTES ESTÉTICAS EN TORNO A LA ÓPERA ESPAÑOLA (1868-1913)}

forma que introduce la sonoridad hispana sutilmente en la voz y la orquesta, sin llegar, no obstante, a explicitarse de forma contundente (Clark, 2002: 152). Este eclecticismo, como el de gran parte de los compositores españoles de esta etapa, funciona dentro de la variedad contrastante de situaciones dramáticas que tienen lugar: "cada situación tiene su colorido propio, el ambiente que le conviene; pero la impresión total es una” (Morphy, 1895: 1).

No obstante, la ópera de Albéniz que va a suponer una total ruptura respecto a los trabajos precedentes fue Pepita Jiméner, escrita en 1895 y estrenada a comienzos del año siguiente también en el Liceo de Barcelona. El contacto con los impresionistas franceses antes mencionados, así como con d'Indy, le posibilitó crear un lenguaje mucho más personal para una obra costumbrista desarrollada en España, unos rasgos que había venido buscando y que se adaptaban perfectamente a su estética: un trasunto local, el de Valera, idealizado, retratado con elementos musicales también idealizados (Clark, 2002: 162). El planteamiento de este drama rural, que se desarrolla en una sola jornada durante una festividad religiosa, acercaba también a la ópera a los planteamientos veristas desarrollados por Leonvacallo y, especialmente, Mascagni (en su Cavalleria Rusticana y, en especial, en L'amico Fritz) (Clark, 2002: 162). Desde el punto de vista orquestal, en esta ópera el compositor desarrolla con mayor agudeza la técnica de los motivos y temas reminiscentes (estos últimos aparecen con mayor profusión), asociados en este caso a personajes y lugares más que a situaciones (quizá con el asesoramiento del propio d'Indy), las cuales aparecen caracterizadas con la transformación de los mismos, en lo que constituye un recurso a medio camino entre la técnica del leitmotiv y el utilizado por los compositores italianos desde Donizetti a Puccini (Clark, 2002: 171). En el terreno vocal, en línea con las óperas compuestas en Europa y también en España, busca una línea cercana al declamado, que cede lugar en determinados momentos a la melodía pura y a la claridad textual, tal y como sucede en las obras del movimiento verista. Sin embargo, y aunque no desprecia el recurso directo o reelaborado del folclore nacional (destaca el uso de la malagueña, transmutada en el contexto de una fuga o utilizada con su función original -en el baile protagonizado por niños en el segundo acto-), la principal aportación de Albéniz con esta ópera es la invención de un lenguaje lírico hispano plenamente idealizado, tomado del cante jondo y del flamenco; y esta es la diferencia que lo aleja de cualquier producción española anterior, pues tanto Pedrell como Serrano, Bretón, Chapí y Giró habían recurrido al lenguaje de la jota, la seguidilla, la habanera, las sonoridades moriscas y demás estilos presentes de un modo u otro en la zarzuela y sus derivados, pero nunca del flamenco y sus palos (Clark, 2002: 312-313). La modalidad (en especial, la frigia), las notas de adorno, los giros cromáticos de carácter andaluz, los ritmos característicos y las "texturas acórdicas y las falsetas características de la guitarra" (Clark, 2002: 179) son utilizados para crear una atmósfera de una honda expresión, como sucede, por ejemplo, en la romanza de Pepita del comienzo del Acto II. De este modo, con Pepita Jiménez. Albéniz ideó el estilo que posteriormente desarrollará plenamente en Iberia, su obra maestra. Se trata, en definitiva, de una obra que inaugura una nueva fase en la historia de la ópera en España, aquella en la que se producirá una búsqueda generalizada de la esencia hispana (ya fuese mediante la fusión del folclore castellano y el lenguaje de la zarzuela con la tradición europea, ya mediante la síntesis del cante jondo y el flamenco con ésta), lo cual pasará, en unos casos, por el recurso 


\section{FRANCISCO M. LÓPEZ GÓMEZ}

a los presupuestos venidos del verismo y, en otros, por la adopción de los principios del modernismo francés y también el neoclasicismo.

A pesar de todo, la última ópera completa de Albéniz, Merlín (compuesta en 1902), se aleja de la senda iniciada en ese buscado nacionalismo de las esencias, para abrazar los preceptos de Wagner como ningún compositor hispano lo había hecho antes. Destinada a convertirse en King Arthur, la que hubiera sido la trilogía inglesa wagneriana por excelencia (las otras óperas debían haber sido Launcelot-inacabada- y Guinevere), está completamente inspirada, tanto dramática como musicalmente, en la tetralogía wagneriana y en el Tristán, obras que conocía a fondo y que admiraba (Clark, 2002: 207-208). Ello se deja ver en la rica orquestación, el protagonismo que adquiere el viento metal, la armonía cromática que prima en todo momento, la continuidad dramática conseguida con la eliminación completa de la estructuración por números y la presentación de una línea vocal casi siempre declamada, y el uso sistemático de leitmotivs en la orquesta, algunos de ellos, al parecer, inspirados directamente en los del Ring y utilizados en el borrador de la segunda ópera de la trilogía (Clark, 2002: 211) ${ }^{56}$. No obstante, Albéniz nunca reniega de su estética, de forma que hace uso de un color hispano idealizado en el tercer Acto de su ópera, acompañando a las sarracenas que danzan lascivamente para intentar seducir a Merlín y que les preste su bastón ${ }^{57}$.

A finales del s. XIX hizo debut en el panorama operístico un compositor ligado también al nacionalismo de Pedrell e inspirado como Albéniz en el folclore andaluz, aunque tendiera, como lo habían hecho el resto de sus compatriotas, a la imitación de la tonadilla y sus derivados. Se trata de Enrique Granados, quien, en 1898, estrenó María del Carmen 58 , acontecimiento que tuvo lugar en el Circo de Parish de Madrid. Se trata de una obra que refleja la formación del compositor de manos de Massenet en el Conservatorio de París, así como la inspiración directa en el folclore murciano, donde viajó Granados para empaparse de la música popular de la región ${ }^{59}$, lugar en que se desarrolla la trama de su ópera. Este hecho lo acerca, más aún que Albéniz, a la ópera verista, al documentarse, al modo de Mascagni, Leonvacallo o Puccini, para buscar la verosimilitud lírico-dramática; de dicha escuela toma también el estilo directo y la orquestación brillante (Bragado, 2003: IX). Asimismo, destaca la caracterización musical de cada uno de los personajes, en especial de la protagonista ${ }^{60}$, así como "la majestuosidad apasionada de Pencho, el amor infinito de

\footnotetext{
56 De clara filiación wagneriana es, por ejemplo, la procesión que sale de la iglesia al inicio de la ópera, que recuerda a la Fiedensmelodie del Acto III de Siegfried (Torres, 1998: 8).

${ }^{57}$ Se trata de un momento que recuerda a muchos críticos al polo que precede el Acto IV de Carmen (Clark, 2002: 214). La danza que le sigue, protagonizada por Nivian, parece inspirada nuevamente en unas malagueñas.

${ }^{58}$ La ópera la compuso Granados a lo largo de 1896, cuando ya se había estrenado Pepita Jiménez. (La Época, 10-10-1896: 3).

59 Allí Granados se empaparía de la música que su anfitrión, el conde de Roche, organizaría, contratando "las típicas parrandas, haciendo ejecutar a los cantores todo el repertorio del país, y formando, para la mejor comprensión, verdaderos cuadros, pues hombres y mujeres se vistieron al efecto los trajes típicos y las ropitas de gala" (Sepúlveda, 1898: 2). No obstante, escribiría su obra en Ripollet, tras su breve estancia en Murcia.

${ }^{60}$ De gran valor, por lo acertada y descriptiva, es la reseña de Muñoz, que aquí copiamos en parte por razones de espacio: "Granados es, como Chopin, el músico delicado de la melancolía y del color. Por eso la figura más vigorosamente destacada de su obra es la de María del Carmen. Le acompaña abrazándola cariñosamente una
} 


\section{CORRIENTES ESTÉTICAS EN TORNO A LA ÓPERA ESPAÑOLA (1868-1913)}

Javier, la delicada ingenuidad de la Fuensantica, flor sencilla y de fragante perfume de las vegas murcianas, [...] la nobleza de Domingo [...] y la rudeza campesina de Pepuco" (Blasco, 1898: 3). No obstante, musicalmente hablando la verdadera influencia que se deja notar en María del Carmen es la del Messidor y Fervaal de d'Indy; asimismo, como podemos observar en óperas como L'Attaque du moulin de Bruneau, Granados concibe en muchos momentos una melodía completamente declamada (sobre un sustento armónico fuertemente cromático) que se adapta a los fragmentos en prosa y no en verso (Barrado, 1898: 2), motivo por el cual fue criticado por un público y parte de la prensa con un gusto fuertemente anclado a la tradición italiana (ver: Licenciado Caja, 1898: 53). Para conseguir la unidad dramática, el compositor hace uso de distintos leitmotiv o, más bien, temas y motivos reminiscentes, en línea con muchas obras del drama operístico moderno. Estos elementos se alternan en la ópera de Granados con dos fuentes: el folclore murciano, abordado, principalmente, desde la perspectiva nacionalista abrazada por compositores como Serrano (uso de la jota, las parrandas, el bolero, el fandango "y las varoniles coplas de las canciones murcianas") (Blasco, 1898: 3), un recurso que en el drama rural de María del Carmen sucede con una gran verosimilitud ${ }^{61}$; y la tonadilla de finales del s. XVIII, un uso consciente de la música histórica que adoptó bajo el influjo de las ideas nacionalistas de Pedrell ${ }^{62}$.

Inmediatamente después de componer su María del Carmen, Granados se embarcó, antes de la concepción de la célebre Goyescas, en la creación de dos nuevas óperas: Petrarca, obra en un acto compuesta en 1899 y que no llegó a estrenarse; y Follet, compuesta entre 1901 y 1902 y estrenada al año siguiente en el Liceo, en una audición privada. Tal y como sucedió con Albéniz, el compositor leridano cambió de rumbo para adoptar el camino del wagnerismo. Sintomático es el hecho de que ambas estén escritas en catalán, siguiendo de nuevo la senda trazada por Pedrell pero olvidando la importancia que éste concedía a los rasgos musicales hispanos diferenciadores. Del compositor alemán adoptó en esta ópera la orquesta romántica ampliada; el uso sistemático de pequeños leitmotiv presentes ya en el preludio y que se desarrollan y modifican a lo largo de la obra ${ }^{63}$; así como el declamado constante que no cede lugar al desarrollo melódico y que presupone la adopción de una

melodía punzante que arranca lágrimas. Es un canto de amor infinito vencido por el sacrificio; este canto se oye siempre, precede y sigue y envuelve a la huertana" (Muñoz, 1898: 2).

${ }^{61}$ Destaca, en este sentido, el dúo de Javier y $\mathrm{M}^{\mathrm{a}}$ del Carmen del primer acto, "inspirado en un cantar de la trilla"; el tema principal que domina en toda la obra, "también una copla antigua del país"; y el acompañamiento orquestal que sustenta la línea declamada de la voz, que imita los punteos de la guitarra (Sepúlveda, 1898: 2). Por otro lado, como apunta Bragado (2003: XII), tanto la "Canción de zagalica" (en estilo de parranda) como la "Canción cartagenera" parecen estar inspiradas en el Cancionero de Inzenga. Otros críticos encontraron muestras del exotismo que caracterizó a compositores como Bizet y Delibes en Carmen y Lakmé, respectivamente (Malats, 1899: 5).

${ }^{2}$ Bragado (2003: XII) ha identificado el uso de la melodía "El fino paño en la tienda".

${ }^{63}$ La técnica de la asociación temática en Petrarca (con su constante modificación y adaptación a cada situación) queda más cercana a los procedimientos de Liszt que de Wagner (Clark, 2016: 108). Sin embargo, en Follet algunos leitmotivs adquieren una verdadera significación dramática y simbólica, como el de la tormenta, que bebe de la tradición verdiana (de óperas como Rigoletto y Otello) y wagneriana (de obras como Tristan und Isolde) (Larrad, 1991: 153-154). 


\section{FrANCISCO M. LÓPEZ GóMEZ}

armonía cromática (Larrad, 1991: 151-152) ${ }^{64}$. No obstante, el primer drama se acerca más a la estética wagneriana, al imbuir al personaje principal en una reflexión constante, que desemboca a veces en lo onírico; por el contrario, Follet está inspirada en la tradición literaria popular de Bretón de los Herreros, en la que el libretista (Mestres, autor de ambos libretos) está inspirado, lo cual lo acerca a óperas como Dinorah de Meyerbeer (Larrad, 1991: 152-153).

Respecto a la generación anterior de compositores, siguió cultivando el género operístico fiel a sus principios estéticos fundados en el eclecticismo, es decir, en el recurso a los distintos procedimientos y técnicas que ya dominaban a la perfección: los desarrollados por los compositores en Europa desde la década de 1830 hasta el presente. Asimismo, se observa en ellos una tendencia general a hacer un uso cada vez más desmedido del folclore hispano, abrazando tanto preceptos de la corriente nacionalista como los de la esencialista. La razón de ello se encuentra, tras los considerables estrenos operísticos que se sucedieron en la década de los 90 en España -junto con los numerosos triunfos alcanzados por diversos compositores en el terreno de la zarzuela en esa misma época-, en una mayor confianza depositada en la ópera nacional, vestida con los ropajes de la música popular española.

El caso de Emilio Serrano es representativo al respecto. En su Gonzalo de Córdoba, compuesta en 1896 y estrenada dos años más tarde con gran éxito en el Teatro Real, vemos a un compositor maduro plenamente confiado en lo que había venido desarrollando desde su Mitrídates y Juana la Loca: el color hispano adoptado tanto desde la óptica descriptivista como la del análisis concienzudo que lo lleva a integrar plenamente estos recursos hispanos en la textura orquestal y en la línea vocal, unos recursos que impregnan toda la obra. En el primer caso, encontramos momentos como las escenas que introducen cada uno de los actos de la ópera, en especial el primero y el segundo (aquí Serrano recurre a una descripción pintoresca con el uso de seguidillas, jotas y zapateados, siempre de nueva creación) ${ }^{65}$; el intermedio que introduce la segunda escena del acto II (construido con ritmos de habanera); así como el uso esporádico de guitarras, introducidas para conseguir un ambiente más auténtico. El segundo caso es perceptible en el uso de enlaces acórdicos propiamente hispanos (como el I-II bemolizado menor con séptima menor), del modo frigio, de ritmos tomados de bailes populares, etc. A pesar de ello, en su obra sigue estando presente el lenguaje europeo, que se alterna con estos momentos de inspiración hispana en un proceso posibilitado por la estructura de este drama histórico, que bebe nuevamente de la tradición italo-francesa de mediados de siglo. En línea con gran parte de las óperas anteriormente analizadas, el dúo de amor del Acto I (entre Elvira y Enrique), de carácter simétrico, presenta una fuerte influencia de la tradición verdiana. Por su parte, los finales de acto siguen estando inspirados en la tradición de la grand opéra, en los que se suceden diversos y tensos acontecimientos en el contexto de una escena monumental (textura

${ }^{64}$ De filiación claramente wagneriana es el dúo que corona el acto central de Follet entre el protagonista y Nadala, similar al que ideó el compositor alemán en el mismo acto de Tristan und Isolde (Larrad, 1991: 153).

${ }^{65} \mathrm{La}$ primera escena del Acto II recuerda a momentos como el inicio del tercer acto de la zarzuela Curro Vargas de Chapí (Fernández Álvarez, 2016: 230). 


\section{CORRIENTES ESTÉTICAS EN TORNO A LA ÓPERA ESPAÑOLA (1868-1913)}

policoral, protagonismo del metal, uso del órgano) ${ }^{66}$, y donde el ambiente religioso y los temas reminiscentes (algunos de ellos nuevamente inspirados en la música popular hispana) adquieren en este caso una entidad fundamental. Este último recurso, tan importante en el resto de la producción operística de Serrano, adquiere en Gonzalo de Córdoba una entidad considerable no sólo por su número, sino por el proceso de transformación y transmutación al que se ven sometidos (muchos de ellos de inspiración hispana), casi siempre en la orquesta y acompañados de un lenguaje armónico y un estilo vocal plenamente contemporáneos y posrománticos, para adaptarse perfectamente a las situaciones, sentimientos, lugares, etc. ${ }^{67}$ Este hecho, junto con los rasgos analizados, sitúan a esta destacada obra de Serrano en una posición de difícil categorización dentro de las tendencias nacionalista y esencialista.

La última ópera escrita por Serrano, La maja de Rumbo68, es la obra de Serrano de mayor inspiración popular, hasta el punto de poder calificarse como una zarzuela con vuelos de ópera, en la misma línea que La Dolores y iTierra!, sobre un drama rural que guarda muchas similitudes con Goyescas de Granados (compuesta al año siguiente) y La vida breve de Falla (en este caso, anterior a la de Serrano). Como sucedió con Albéniz en su Pepita Jiménez, el compositor alavés encontró en este drama ${ }^{69}$ desarrollado en el Madrid de finales del s. XVIII una verdadera fuente de inspiración de su musa folclórica, haciendo uso del lenguaje cercano a la tonadilla que habían utilizado compositores desde Barbieri a Chapí, Bretón y Chueca: seguidillas, boleros, melodías ligeras en $6 / 8$, puntos de conexión con el lirismo italiano más puro, etc. ${ }^{70}$. Esto no obsta para que Serrano recurra, fiel a sus ideales dramáticos, al uso de temas recurrentes (casi todos también de inspiración popular), que adquieren similar entidad que en óperas precedentes, transformándose, transmutándose e, incluso, yuxtaponiéndose; ni tampoco para que, en algunos momentos, el compositor se acerque al esencialismo teorizado por Pedrell, imbuyendo los sonidos hispanos ${ }^{71}$ en las ricas armonías del modernismo europeo (sin sobrepasar nunca los límites de lo tonal); así como tampoco obsta para el recurso a ambientaciones oscuras en interludios al modo de Gounod (eso sí, con presencia también de sonoridades hispanas) o el uso de un lenguaje armónico avanzado y de carácter eminentemente cromático para las escenas de mayor dramatismo (en especial, en el último acto). El carácter y la estética de la obra nos remiten, en ocasiones, al Verdi de Falstaff (en la misma línea que el genio italiano encontramos la

\footnotetext{
${ }^{66}$ Destaca, en este sentido, el final del último acto, cuya escena amorosa en un contexto religioso circunscribe acertadamente Fernández Álvarez (2016: 251) a la tradición de las óperas de Meyerbeer y de otras como La Juive de Halèvy o La Gioconda de Ponchielli, pero también otras a nivel nacional como La Dolores y Los amantes de Teruel de Bretón, o Margarita la Tornera de Chapí.

${ }^{67}$ Ver el análisis al respecto realizado por Fernández Álvarez (2016: 224-238).

68 "Comedia musical" compuesta en 1810 y estrenada el mismo año en el Teatro Colón de Buenos Aires, junto con Margarita la Tornera de Chapí, La Dolores de Bretón y Els Pirineus de Pedrell.

${ }^{69}$ En realidad, la calificación de esta ópera como comedia o drama está supeditada a la versión a la que nos refiramos de las dos existentes: una con final trágico debido a la muerte de la protagonista (versión primigenia) y otra que culmina en boda.

${ }_{70}$ Ver el análisis de la ópera realizado por Fernández Álvarez (2016: 310-337).

${ }^{71}$ A los elementos utilizados anteriormente por Serrano, cabe añadir el uso de la línea de bajo de fandango, de sonidos derivados del flamenco, tiranas, etc.
} 


\section{FRANCISCO M. LÓPEZ GÓMEZ}

perspicaz musicalización del texto y la adaptación a cada uno de sus matices) $)^{72} \mathrm{o}$ al de Gianni Schichi de Puccini. No obstante, a nuestro juicio el mayor mérito de esta última ópera de Serrano es el original uso que hace del folclore gracias a la madurez alcanzada, que le permite utilizarlo con la misma efectividad tanto en contextos festivos y cómicos como en los momentos de mayor dramatismo ${ }^{73}$.

Respecto a Tomás Bretón, prosiguió su lucha vitalicia en defensa de la ópera nacional, produciendo en estos inicios del s. XX cuatro nuevas óperas. La primera de ellas, Raquel ${ }^{74}$, supone un cambio de rumbo respecto a su ópera anterior (La Dolores), tal y como habían experimentado Albéniz y Granados, abandonando la vía verista así como, en gran medida y a consecuencia de ello, la corriente nacional. La única referencia hispana la encontramos en los cantos hebreos -caracterizados con el uso de acordes huecos y giros modales- sobre los que se documentó Bretón personalmente para dotar de verosimilitud musical a su obra (Sánchez, 2002: 295-301), así como en la sonoridad "alhambrista" (utilizada para caracterizar lo oriental, como la escena de las esclavas, pero también al personaje de Raquel, como puede verse en su aria del tercer acto) (Sánchez, 2002: 303-304). Destaca, por otro lado, el uso de una orquestación más reducida y selectiva, lo cual no lo alejaba en exceso de las prácticas que se estaban empezando a cultivar en Europa, a las que se adscribe también Bretón con el uso de una armonía en línea con el modernismo francés ${ }^{75}$. De gusto francés son también momentos como el dúo entre Raquel y David del primer acto, que no obedece a ninguna estructura preestablecida y está ricamente acompañado por la orquesta, el racconto de Raquel del final del segundo acto, de gran originalidad, el intermezzo orquestal del tercer acto (al modo de los de Serrano), y, por supuesto, el recurso a exóticas danzas orientales que preceden al dúo de amor del tercer acto (este, por el contrario, de ascendencia italiana; Sánchez, 2002: 305), procedimiento común a gran parte de los compositores españoles para este tipo de escenas, como hemos ya comprobado, las cuales, por su sonoridad (profusión de floreos cromáticos, uso del segundas aumentadas y del modo frigio) "recuerdan las sonoridades andalucistas de Falla o Albéniz" (Sánchez, 2002: 305).

En una línea similar encontramos su siguiente ópera, Farinelli, compuesta en 1902 y estrenada el mismo año, junto con Circe de Chapí, por la célebre empresa del Teatro Lírico destinada a cultivar el drama nacional. Basado en una ficticia historia de amor del castrato

\footnotetext{
72 Un buen ejemplo de ello es el momento que describe los sentimientos del Zaque a lo largo de la primera escena de la ópera, así como el motivo "chispeante" que rige el dúo de Salud y Zalamero de la escena siguiente. Ver: Fernández Álvarez (2016: 315).

${ }^{73}$ Destacan, en este sentido, lugares como el que describe el cinismo del Zaque al final del primer acto, a través de una interesante variación armónica y modal del motivo de la tirana. Ver: Fernández Álvarez (2016: 320). Dicha tirana cobrará protagonismo en otras muchas escenas de la ópera, mostrándose siempre adaptada a cada una de las situaciones.

${ }^{74}$ Compuesta entre 1898 y 1899, esta ópera en cuatro actos consiguió estrenarla al año siguiente en el Teatro Real de Madrid.

${ }^{75}$ Momentos como el inicio del Acto II, con participación en escena de distintos estratos sociales y donde se discute la expulsión de los judíos, podría haber proporcionado a Bretón la ocasión para componer una página de gran monumentalidad al modo de la grand opéra, pero, en su lugar, crea una pieza sin grandes pretensiones, "de gran sencillez y sonoridad" (Bretón, 1900: 1). Citado por Sánchez (2002: 303). Ver también: González (1900: 3). Citado por Sánchez (2002: 305).
} 


\section{CORRIENTES ESTÉTICAS EN TORNO A LA ÓPERA ESPAÑOLA (1868-1913)}

Carlo Broschi, el drama brinda nuevamente a Bretón la oportunidad de hacer uso de una ficticia verosimilitud histórica, de forma que recurre en algunos momentos (como, en especial, en el aria del prólogo) (Sánchez, 2002: 328) a un estilo vocal melismático de considerable coloratura para caracterizar al castrato, personaje travestido (soprano). Sin embargo, lo que más destaca de esta obra es la fusión que consigue el compositor entre lo cómico y lo dramático, que se confunden y entremezclan ingeniosamente sin solución de continuidad como sucede en obras como Falstaff, así como la originalidad de la música (que no busca grandes pretensiones armónicas ni orquestales), difícil de encuadrar estéticamente y concebida para adecuarse a la peculiaridad del drama, nada convencional, aunque en muchos puntos, por el lenguaje vocal que busca el lirismo para intensificar la expresión de los personajes, se acerca a la estética verista (Sánchez, 2002: 329).

La siguiente ópera de Bretón, Don Gil de las calzas verdes ${ }^{76}$, se adscribe a la escasa tradición de óperas cómicas españolas como la casi contemporánea Maja de Rumbo. Sin embargo, reflejo de sus ideales contrarios a los de Serrano (como hemos visto, éste tendería cada vez más a utilizar el folclore hispano), Bretón no renunciaría en tanta medida al uso del lenguaje internacional. No obstante, a diferencia de primero la orquestación es mucho más reducida y ligera, permitiendo sobresalir a la voz en todo momento (Sánchez, 2002: 409) y ofreciendo un estilo que en algunas ocasiones es deudor de la zarzuela de comienzos de siglo. Esto no es obstáculo para demostrar un gran manejo orquestal y contrapuntístico, utilizado con maestría en las escenas cómicas (Sánchez, 2002: 411); ni tampoco para incluir un nocturno (el del tercer acto) de gran interés y originalidad por el trabajo armónico que muestra (Sánchez, 2002: 411). El pretendido historicismo queda también patente en el uso de una pavana al final del primer acto, así como de una armonía de gran claridad tonal (si bien aparece en muchos lugares ricamente adornada), propia no obstante del estilo de las óperas cómicas de finales del s. XVIII, donde asoma la personalidad de Mozart (en especial su habilidad para caracterizar las escenas cómicas) ${ }^{77}$.

A la altura de 1913, Bretón compuso y estrenó (nuevamente en el Real) su última ópera, Tabaré, inspirada en el poema del uruguayo Juan Zorrilla de San Martín sobre la conquista española de América. Si en el resto de compositores la tendencia había sido el uso cada vez más acentuado del color hispano, en el autor salmantino, que siempre puso sus miras en Europa, éste se hace presente únicamente cuando la situación lo requiere. En este caso, el mérito de Bretón está en la caracterización de lo tribal frente a lo español/civilizado, que se traduce respectivamente en la contraposición del pentafonismo, el dominio de las maderas frente a la cuerda, lo cromático, e incluso, atonal y complicadas polirritmias que describen danzas tribales (Sánchez, 2002: 422-423) -lo cual acerca tímidamente a esta obra a Stravinsky, si bien La consagración de la Primavera es estrictamente contemporánea- (Sánchez, 2002: 423), por un lado, y de fanfarrias, marchas militares y

\footnotetext{
76 Esta "ópera cómica”, inspirada en la conocida comedia de Tirso, fue compuesta entre 1908 y 1910 y estrenada cuatro años más tarde en el Tívoli de Barcelona.

${ }_{77}$ Sánchez (2002: 411) establece un paralelismo entre los concertantes finales del segundo y tercer acto y los del mismo lugar de Las bodas de Figaro, obra mozartiana que conocía el compositor salmantino.
} 


\section{FRANCISCO M. LÓPEZ GÓMEZ}

sonoridades hispanas (modo frigio, sonidos provenientes del flamenco, etc.), por el otro $^{78}$. Asimismo, acorde con el lenguaje armónico analizado, domina el tratamiento declamado de la línea vocal, que, en el caso de la destinada al barítono, requiere una gran fuerza y amplio registro, motivo por el cual encuentra Sánchez paralelismos con el Otello de Verdi (Sánchez, 2002: 423). No obstante, no llega a renunciar, en los momentos que lo requieren (en especial, las escenas amorosas) al lirismo al modo de las óperas veristas de Puccini de principios de siglo. Por otro lado, destaca el uso de leitmotivs, algunos de muy corta extensión, como el diseño de tres notas que aparece ya en la extensa obertura y que cobrará un gran protagonismo en el último acto, lo cual lo acerca a los procedimientos wagnerianos, en especial, del Tristán (Sánchez, 2002: 425), por su eminente carácter cromático y disonante. Por los elementos mencionados, por el ingenioso uso de temas y motivos recurrentes, y por la intensidad dramática conseguida, especialmente en el último acto, con un lenguaje plenamente wagneriano, se trata de una de las obras más destacadas dentro de la producción de Bretón.

Tras una larga etapa retirado del género operístico para dedicar todos sus esfuerzos a la regeneración de la zarzuela (lo cual consiguió triunfantemente), Chapí regresó a la palestra de la ópera nacional, la que constituyó de joven su principal aspiración. Lo hizo, auspiciado por las esperanzas con que muchos vieron el Teatro Lírico, con su ópera de argumento mitológico Circe ${ }^{79}$. Chapí, como, en cierto modo, Bretón, seguía entendiendo la ópera como un género totalmente diferenciado del de la zarzuela, de modo que partió del ideal estético que abandonó con su Roger de Flor, haciendo uso de una variedad de estilos y técnicas que le permitieran poner en música cada una de las situaciones del drama. En Circe encontramos dominante el lenguaje de los modernistas franceses (Saint-Saëns, Massenet, d'Indy) ${ }^{80}$; pero Chapí también se retrotrae -como no podía ser de otro modo en una ópera de este trasunto- al gusto francés por lo exótico, utilizando bailables en el tercer acto al modo de Aida o de la bacanal del Samson ${ }^{81}$. No obstante, partiendo de estos principios busca en muchos momentos la sencillez, evitando en la orquesta "aglomeraciones [o...] efectazos de relumbrón” (Muñoz, 1902: 2; Cortès, 2012: 174-179), especialmente en el segundo acto, donde domina el lirismo propio de las óperas veristas coetáneas de Puccini. A pesar de ello, la sonoridad que más domina es la de corte wagneriano, tanto en el estilo declamado que permite el desarrollo de la acción principal (a él pretendió acercarse ya en su ópera Roger), como en el lenguaje armónico, cromático y constantemente modulante, el uso de ciertos leitmotiv, algunos de cierta semejanza con los de Tristan und Isolde (Cortès, 2012:

\footnotetext{
${ }_{78}$ Estos rasgos aparecen asociados especialmente a la figura de la española Blanca, enamorada del caudillo Tabaré, que aparece impregnada en su romanza del color popular hispano.

${ }^{79}$ Compuesta en 1902 y estrenada el mismo año en dicho teatro.

${ }^{80}$ De corte francés es el coro de mujeres del inicio del Acto II, "gracioso y elegante, que bien pudiera firmar Saint-Saëns"; también lo es la melodía asignada al violoncello en uno de los momentos culminantes, el que describe a Circe intentando conquistar a Ulises, y que se convierte en un tema recurrente ya que "simboliza el amor de los protagonistas" (Mitjana, s.f.: 84). La dulce berceuse que canta la protagonista, contemplando gozosa a Ulises mientras duerme, bebe de la tradición del Saint-Säens de Samson et Dalila y La Princesse jaune; y el dúo "Agradecido estoy a tus mercedes" está en línea con el estilo de Massenet (Iberni, 2009: 347-350).

${ }^{81} \mathrm{El}$ uso de estas sonoridades -en este caso, de una escala tetratónica- en el contexto de un bailable exótico para caracterizar lo oriental lo encontramos ya en La hija de Jefté, reutilizado después por Chapí, sin introducir cambio alguno, en Roger de Flor.
} 


\section{CORRIENTES ESTÉTICAS EN TORNO A LA ÓPERA ESPAÑOLA (1868-1913)}

174), así como en el tratamiento coral82 (un rasgo que vemos, de igual modo, en su ópera Roger, en especial en el coro que da fin a la obra ${ }^{83}$. Todo ello no es óbice para que Chapí renuncie por completo a la tradición hispana, de forma que en el segundo acto inserta un cuarteto de "cantoras" inspirado en el lenguaje de la tonadilla del s. XVIII, quizá el número que mayor éxito alcanzó.

El mismo principio dramático encontramos en su última obra, la célebre Margarita la Tornera (1909), que, por el trasunto, ofrecía la posibilidad de romper con los moldes operísticos decimonónicos, pero que sigue fundándose en la ley de la variedad y el contraste $^{84}$. No obstante, el maduro Chapí ya no hace el tradicional uso de las arias, dúos, tercetos y números corales (los conjuntos directamente no existen, salvo dos contadas excepciones, en las que presenta un lenguaje cómico similar al Manon Lescaut, al Falstaff, a Die Meistersinger von Nürnberg o a Till Eugelspiegel (Iberni, 2009: 525-530); podríamos añadir a este elenco a nivel nacional, obras como Farinelli o La maja de Rumbo, esta última tan solo un año posterior a la de Chapí, si bien la factura de este último bebe mucho más, por su nutrida orquestación, de la de Richard Strauss). Así, en su última ópera domina en todo momento el estilo declamado, sacrificando con ello la melodía a favor de la claridad textual, y esto lo aplica tanto a los momentos en los que la orquesta es tratada a la manera wagneriana, como en otros donde el elemento característico hispano se funde en la textura tanto de la orquesta como de la línea vocal, lo cual sitúa a esta obra en una posición a tener en cuenta dentro del nacionalismo de las esencias. No obstante, en algunos lugares no renuncia tampoco al lenguaje directo y sencillo de la tonadilla y de la zarzuela que tanto había desarrollado en su carrera, y que se muestra tanto en el comienzo como en el final del segundo acto (Iberni, 2009: 524-525) ${ }^{85}$; del mismo modo, recurre a la tradición de la ópera cómica del clasicismo, de la que toma el estilo del Don Giovanni mozartiano (Iberni, 2009: 528). Las páginas magistrales de la obra, culmen de la producción operística de Chapí, se encuentran en el último acto, al que consigue imprimir ese misticismo y recogimiento que demandaba el libreto, alrededor tanto del personaje de Margarita (testigo principal del milagro) como de Don Juan (invadido por el sentimiento de soledad y amargura) ${ }^{86}$. Se trata de momentos que comparten en carácter y estilo con Suor Angelica de Puccini (Iberni, 2009: 529), por un lado, y con Parsifal (Casares, 2012: 152), por el otro, y que sirven de precedente a Granados en Goyescas y a Falla en El sombrero de tres picos (Iberni, 2009: 529).

En cuanto a Pedrell, concebiría a principios de siglo sus dos últimas óperas: $L a$ Celestina y El comte Arnau, compuestas en 1902 y 1903 respectivamente, y que, tras varias

\footnotetext{
82 Momentos cercanos a la Tetralogía los encontramos especialmente en el primer y tercer acto. Destaca, en este sentido, el que describe la entrada heroica en escena de Ulises, que se asemeja al de Wotan en el final de Die Walküre. Asimismo, el momento de la aparición de la sombra de Aquiles es muy cercano, por el estilo declamado y la estructuración que presenta, al de la hija de la Erda de Das Rheingold. Finalmente, el monólogo de Circe del último acto muestra algunos paralelismos con el de la inmolación de Brunnhilde de Götterdämmerung. Ver: Iberni (2009: 349-352).

83 Ver: López (2016: 768-769).

84 Ver el estudio al respecto realizado por Iberni (2009: 512-514).

85 Inspirado en la zarzuela grande de la década anterior está claramente el dúo de Margarita con su enamorado, D. Juan, construido alrededor de una melodía desenfadada dotada de gran lirismo.

86 Ver el análisis realizado por Iberni (2009: 521).
} 


\section{FrANCISCO M. LÓPEZ GóMEZ}

tentativas infructuosas, nunca llegaron a ponerse en escena. En la primera de ellas encontramos a un compositor que ha madurado y evolucionado respecto a la monumental obra de Els Pirineus, de forma que el tratamiento armónico es mucho más rico, así como los detalles rítmicos; y el coro ya no actúa como medio para conseguir esa monumentalidad, sino como elemento de color, camuflándose con el resto de la orquesta o, para el caso del Comte Arnau, ejerciendo la función de guía del argumento como en la tragedia griega (Cortès, 1991-2: 82-88). Por otro lado, la relación entre música y texto es mucho más estrecha, lo cual, tratándose de una obra escrita enteramente en prosa ${ }^{87}$, conllevaba el uso de una línea vocal que busca siempre el estilo declamado. Otra consecuencia directa, tanto para La Celestina como para su última ópera (a pesar de sus temáticas tan opuestas), era el uso sistemático y extensivo (diseña un mayor número respecto a Los Pirineos) del leitmotiv,

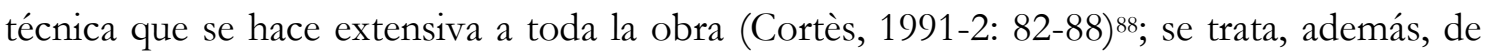
unos motivos mucho más afines, por su carácter y potencial de desarrollo ${ }^{89}$, a los concebidos por Wagner, aunque en ocasiones la técnica de transformación temática esté más cercana a Liszt y Berlioz (Cortès, 1991-2: 67-68). Si atendemos a la trama argumental, la estética wagneriana se adaptaba, además, perfectamente al Comte Amau, por el elemento fantástico que domina (bosques sombríos y tétricos, tormentas, orgías, visiones, el mundo onírico, etc. $)^{90}$. Junto a la influencia del genio alemán, destaca el uso del color hispano, que, a pesar de sus ideas volcadas en su opúsculo Por nuestra música, bebe en algunos momentos directamente del folclore nacional; en otros, no obstante, consigue imprimir a su partitura una original muestra de la esencia de lo hispano. Un ejemplo en este sentido es el uso que Pedrell hace de las coplas del labrador "La cançó del Comte Arnau". Consecuente también con su estética nacionalista es el recurso a la música del pasado, de forma que utiliza fuentes tan variadas como adaptaciones de madrigales de Palestrina, un falso bordón de Tomás de Sancta María del 1565 o la canción francesa "Mort de Na Joana" (Cortès, 19912: 82-84).

La última figura que trataremos en este artículo es la de Falla, que a comienzos de siglo debutaría también en el terreno operístico con su célebre ópera La vida breve $e^{91}$ y a la que aludiremos (a pesar de los estudios existentes sobre la obra lírica del compositor) ${ }^{92}$ con el objetivo de enmarcarla en el panorama operístico nacional que hemos descrito. El esfuerzo tanto de manos del compositor como del libretista Fernández Shaw por caracterizar este drama desarrollado en la pintoresca y costumbrista Granada, sitúan a la

87 Recordemos que un antecedente inmediato en el panorama hispano fue María del Carmen de Granados (1898), si bien en esta última el uso de la prosa no se hace extensivo a toda la obra.

${ }^{88}$ No obstante, en El Comte Arnau sólo hace uso de un leitmotiv, derivado del célebre acorde de Tristán, que aparece, eso sí, en numerosas ocasiones (Cortès, 1991-2: 93-95).

${ }^{89}$ De César Cui tomaría Pedrell los consejos que le llevaron a idear motivos mucho más reducidos y con potencial para poder desarrollarse constantemente (Cortès, 1991-2: 90-91).

${ }_{90}$ Influido e impresionado por el tema de las llagas de Amfortas de Parsifal, escribió algunas páginas de El Comte Arnau (Cortès, 1991-2: 95).

91 Compuesta en gran parte entre 1904 y 1905, no pudo verla estrenada hasta 1913 en Niza, tras un periodo de revisión que se extendió desde 1910 hasta la fecha de dicho estreno. Al año siguiente, fue ofrecida en la Opéra Comique de París con el mejor reparto con el que se podía contar. Ver: Torres Clemente (2007: 7281).

92 Destacan el trabajo aludido de Torres Clemente (2007), así como el de Weber (2000) y también Hess (2001). 


\section{CORRIENTES ESTÉTICAS EN TORNO A LA ÓPERA ESPAÑOLA (1868-1913)}

obra en una posición a caballo entre el verismo de Mascagni y Leoncavallo (especialmente la Cavalleria rusticana del primero) y el exotismo postergado por la tradición de la grand opéra y de la opéra comique francesas ${ }^{93}$. No obstante, en la partitura de Falla no está presente ese ambiente alegre, ligero y popular que encontramos en Mascagni, sino que domina en toda la obra, especialmente en torno a la familia gitana, un profundo sentimiento de tristeza y nostalgia (Salvetti, 1987: 132). Bajo los ideales del nacionalismo pedrelliano ${ }^{94}$, esta caracterización es la que permite a Falla, precisamente y con gran verosimilitud, dotar tanto a la voz como a la orquesta de un color hispano reinventado tomado del flamenco (cadencias andaluzas, giros melódicos, células rítmicas y formas cadenciales característicos de este género, imitación del rasgueo de la guitarra, así como gritos y frases características), tal y como había realizado años atrás Albéniz en Pepita Jiménez, de modo que fusiona esta sonoridad andaluza con el modernismo francés (no sólo de Massenet, sino, especialmente, Dukas y Debussy, influjo de este último que aún no había experimentado Albéniz; Hess, 2001: 32-34) y el lenguaje de Puccini (Sala, 1987: 122-123). Con ello, bajo los preceptos de la "disciplina, pureza y severidad" aplicados al carácter meridional (en este caso, del andalucismo), el compositor gaditano se introduce de lleno en la estética del neoclasicismo (Hess, 2001). Pero la presencia de la esencia española, especialmente a través del cante jondo, no sólo se restringe al personaje de Salud y de sus allegados, sino que se muestra plenamente desarrollada en el intermedio orquestal central y la fiesta (con danzas y cantos) que sucede con motivo de la boda de Paco y Carmela, en la que tiene lugar una seguiriya, una solea ${ }^{95}$, una jabera y un zorongo gitano -todos ellos aparecen desvirtuados y adaptados al resto del estilo dominante- (Torres Clemente, 2007: 213-224), lo cual provoca la interrupción momentánea del tiempo dramático como sucedía con el ballet de la ópera francesa, de Meyerbeer a Verdi (Salvetti, 1987: 132-133) ${ }^{96}$. Eso no obsta para que no encontremos referencia a Wagner en La vida breve, sino que su presencia se hace notable (la del Tristan y Parsifal) en momentos de gran dramatismo como en los dúos entre Paco y la Abuela y entre Salud y Paco, y en el desenlace que narra la muerte de la protagonista (Salvetti, 1987: 138). En la misma línea, es fundamental en la obra la presencia del trágico motivo conductor de "la vida breve", que "persigue a Salud allá por donde va", siendo sometido a modificaciones considerables para adquirir un papel dramático (Torres Clemente, 2007: 194-196).

\footnotetext{
${ }^{93}$ Las posturas divergen en este sentido. Ver al respecto, las ideas desarrolladas por Torres Clemente (2007: 48-56) a favor de la influencia verista, frente al ingenuo exotismo defendido por Salvetti (1987: 121-123) y Sala (1987: 124-128).

94 De Pedrell recibió Falla consejo a lo largo de la composición de la obra, no tanto de los principios wagnerianos, sino de sus ideas relativas a la reinvención del folclore como el camino más adecuado para la creación de la ópera nacional (Torres Clemente, 2007: 63).

${ }^{95}$ En este caso, se trata de una soleá tomada del Cancionero de Ocón y también modificada por Falla. Ver: García Matos (1971: 190).

${ }^{6}$ De hecho, la composición de estas danzas fue abordada por Falla bajo la influencia directa de Dukas y Debussy, así como, en parte, bajo la sugerencia de André Messager, el entonces director del Teatro Nacional de la Ópera de París (Torres Clemente, 2007: 225-228).
} 


\section{FRANCISCO M. LÓPEZ GÓMEZ}

\section{CONCLUSIONES}

A partir de 1868, a lo largo de apenas media centuria, se desarrolló en España lo que podríamos denominar la edad de oro de la ópera nacional. Prácticamente todas las grandes personalidades españolas del mundo de la composición se preocuparon por el asunto de la ópera, lo que les condujo a crear trabajos de primer orden que, no obstante, fueron menospreciados y, por tanto, olvidados, motivo por el cual la gran mayoría son aún desconocidos. El tesón de muchos de ellos, a pesar de las dificultades y constantes frustraciones, no obedece sino al deseo de regenerar la música española, que, a juicio del público, la crítica y muchos de los compositores, estaba en un estado deplorable en comparación con Centroeuropa.

Bajo este ideal se fueron enraizando diversas tendencias (tanto desde el punto de vista teórico como práctico) orientadas, en términos generales, a la valoración y final aceptación de las sonoridades hispanas, de forma que sobre la corriente europeísta se fue abriendo camino la nacional y, finalmente, la esencialista. Así, en un primer momento, durante la década de los 70, el elemento hispano (proveniente del folclore o bien de la tradición de la zarzuela) era tímidamente contemplado, inserto en las obras con el fin de imprimirles cierto color local en algunos momentos determinados; los modelos eran, pues, la ópera italiana y francesa de mediados de siglo, así como el Wagner romántico. Los siguientes quince años supusieron una fase de experimentación (ésta condujo inevitablemente en muchos casos al eclecticismo, si bien plenamente adaptado al drama), que operó tanto en los momentos de buscada sonoridad "universal" (tomando como modelo las aportaciones más contemporáneas venidas de Francia, el wagnerismo y, finalmente, el verismo), como en la adopción del sustrato hispano (en este caso, mediante la cita literal o elaborada, la fusión con el estilo italiano, o la búsqueda de una sonoridad hispana estilizada, ya fuera inspirada en el folclore castellano, en el andaluz, en la tonadilla o en la música anterior al XIX), auspiciada en este último caso por la adopción de una postura nacionalista que depositaba su confianza en el potencial del arte nacional. Finalmente, la concepción de Pepita Jiménez en 1895 marca un hito que abrirá el camino del esencialismo hispano buscado ya antes por otros compositores (como Serrano, Pedrell o Giró), de forma que la fusión del folclore castellano y andalucista con la tradición culta europea permitirá conseguir momentos en las óperas de gran originalidad. Por supuesto, esta sonoridad la encontramos sin menoscabo del recurso en determinados momentos al folclore reinventado o a sonoridades venidas de la zarzuela, ni tampoco de la adopción de muy diversos lenguajes (en línea con las múltiples tendencias que se estaban desarrollando en Europa), desde el Posromanticismo hasta el neoclasicismo, pasando por el modernismo francés y el wagnerismo. 


\section{CORRIENTES ESTÉTICAS EN TORNO A LA ÓPERA ESPAÑOLA (1868-1913)}

\section{BIBLIOGRAFÍA}

Alonso, C. (1996). "Ruperto Chapí ante la encrucijada finisecular". Cuadernos de música iberoamericana, 1, pp. 165-186.

Archivo de la Real Academia de Bellas Artes de San Fernando, Leg. 335-1/5.

Archivo de la Real Academia de Bellas Artes de San Fernando, Signatura 6-82-1.

Arnedo, L. (1887). “Teatros. La ópera cómica española Un Rapto y el maestro Nicolau (II)". Diario oficial de avisos de Madrid, 10-03-1887, pp. 1-2.

Arrieta, E. (1853). "Revista musical”. La Nación, 21-04-1853, p. 3.

Arrieta, E.; Romero y Andía, A; y Eslava, H. (1867). "Ópera seria española”. Revista y Gaceta Musical, 08-12-1867, pp. 262-263.

Asmodeo [R. de Navarrete] (1877). “Cartas de Asmodeo”. La Época, 26-07-1877, p. 1.

Barrado, A. (1898). “La música de María del Carmen”. La Época, 14-11-1898, p. 2.

Blasco, R. (1898). "Parish: María del Carmen". La Correspondencia de España, 13-11-1898, p. 3.

Bonastre, F. (2002). "El planteamiento operístico de Pedrell”, en E. Casares y A. Torrente (eds.), La ópera en España e Hispanoamérica, pp. 187-197. Madrid: ICCMU.

Bragado, M. (ed) (2003). “Introducción”, en E. Granados, María del Carmen, ópera en tres actos. Madrid: ICCMU.

Bretón, T. (1885). "El príncipe de Viana”. El Liberal, 07-02-1885, p. 2.

[Bretón, T.] (1900). "La Raquel de Bretón”, Heraldo de Madrid, 19-01-1900, p. 1.

Budden, J. (1985). Le opere di Verdi, vol. I. Torino: Edizioni di Torino.

Casado del Alisal, J. (1877). “Informe trimestral. Roma, 12-12-1876 y 12-03-1877”. Archivo Histórico del Ministerio de Asuntos Exteriores.

Casamitjana, J. (1871). La España Musical, 18-05-1871, p. 4.

Casares, E. (1995). "La música del siglo XIX español. Conceptos fundamentales", en E. Casares y C. Alonso (eds.), La música española en el siglo XIX, pp. 13-122. Oviedo: Universidad de Oviedo.

Casares, E. (2012). “Chapí y la ópera”, en V. Sánchez, J. Suárez y V. Galbis (coords.), Ruperto Chapi: nuevas perspectivas, pp. 107-154. Valencia: Institut Valencià de la Música. 


\section{FRANCISCO M. LÓPEZ GÓMEZ}

Clark, W. A. (2002). Isaac Albéniæ: retrato de un romántico, Madrid: Turner (trad. Paul Silles).

Clark, W. A. (2016). Enrique Granados: poeta del piano. Barcelona: Boileau (trad. Patricia Caicedo).

Cortès, F. (1991-2). "La música escénica de Felip Pedrell: Els Pirineus. La Celestina. El Comte Arnau”. Recerca Musicològica, vol. XI-XII, pp. 63-97.

Cortès, F. (1995). El nacionalisme musical de Felip Pedrell a través de les seves òperes: Els Pirineus, La Celestina $i$ El Comte Arnau [Tesis Doctoral]. Bellaterra (Barcelona): Publicacions de l'Universitat Autònoma de Barcelona.

Cortès, F.; y Colomer, E. (eds) (2004). "Introducción”, en F. Pedrell. Los Pirineus, ópera en tres actos. Madrid: ICCMU.

Cortès, F. (2012). "De walkyrias a hechiceras: alrededor de las nociones de wagnerismo y mediterraneidad en la ópera Circe de Chapí y Ramos Carrión”, V. Sánchez, J. Suárez y V. Galbis (coords.), Ruperto Chapi: nuevas perspectivas, pp. 157-179. Valencia: Institut Valencià de la Música.

Diario Oficial de Avisos de Madrid, 12-05-1871. "Centro Artístico-Literario: primera función de ópera española”, p. 4.

Diario Oficial de Avisos de Madrid, 31-05-1871. "Teatro de la Alhambra: Centro artísticoliterario", p. 4.

Diario Oficial de Avisos de Madrid, 10-02-1885. “Teatros: Real”, p. 3.

E. F. “Los estrenos. Tívoli: Un rapto de los Sres. Nicolau y Colomé”. La Dinastía, 06-121887, p. 2.

El Día, 03-02-1885. "Noticias de espectáculos. Teatro Real: El príncipe de Viana, ópera en tres actos original de D. Mariano Capdepón, música del maestro D. Tomás Fernández Grajal”, p. 3.

ElDía, 10-05-1895. "Noticias de espectáculos: la ópera de Albéniz”, p. 4.

El Imparcial, 23-04-1877. “Sección de espectáculos", p. 2.

El Imparcial, 15-11-1881. "Teatro de Apolo: Sagunto", p. 5.

El Imparcial, 15-01-1882. "Mitridate, ópera en tres actos, letra de D. Mariano Capdepón, música del maestro don Emilio Serrano", p. 3. 


\section{CORRIENTES ESTÉTICAS EN TORNO A LA ÓPERA ESPAÑOLA (1868-1913)}

El Imparcial, 03-02-1885. “Sección de espectáculos. Teatro Real: Elpríncipe de Viana, letra de D. Mariano Capdepont [sic], música del maestro Fernández Grajales [sic]”, p. 3.

El Pabellón Nacional, 08-03-1887. "Noticias de Teatros. Circo de Price: Un Rapto”, p. 3.

El País, 06/03/1887. “Teatro Circo de Price”, p. 3.

El País, 07/10/1894. "Noticias de espectáculos”, p. 1.

Eme. (1893a). "Madrid teatral: Manuel Giró”. El Día, 14-05-1893, p. 1.

Eme. (1893b). "El sombrero de tres picos". El Imparcial, 15-05-1893, p. 1.

Esperanza y Sola, J. Ma. (1891). "Revista musical”. La Ilustración Española y Americana, 22-021891, pp. 114-115.

Esperanza y Sola, J. Ma. (1895). "Revista musical". La Ilustración Española y Americana, 30-041895, pp. 272-274.

Esteban y Gómez, J. (1878). “Crónica musical. Teatro Real: primera representación de la ópera del maestro Chapí, Roger de Flor". Revista Contemporánea, 14-02-1878, pp. 376384.

Fargas y Soler, A. (1874). "L'ultimo abenzerraggio, drama en cuatro actos de D. F. Fors de Casamayor, música del maestro Felipe Pedrell”. La España Musical, 02-05-1874, pp 45 .

Fernández Álvarez, E. (2016). Emilio Serrano y el ideal de la ópera española [Tesis doctoral]. Universidad Complutense de Madrid.

Fernán Flór[ez, I.]. (1885a). “El problema”. El Liberal, 09-02-1885, p. 2.

Fernán Flór[ez, I.]. (1885b). “El libro del año”. La Ilustración Ibérica, 14-02-1885, p. 99.

García Matos, M. (1971). "El folclore en La vida breve de Manuel de Falla", Anuario Musical, 26, pp. 173-197.

Goizueta, J. Ma. (1882). “Teatro Real. Mitrídates”. La Época, 19-01-1882, p. 3.

González, E. (1900). “Teatro Real: Raquel’, La Correspondencia de España, 21-01-1900, p. 3.

Hess, C. A. (2001). Manuel de Falla and Modernism in Spain (1898-1936). Chicago: The University of Chicago Press.

Iberni, L. G. (1995a). "El problema de la ópera nacional española en 1885”. Cuadernos de Arte, 26, pp. 219-228. 


\section{FRANCISCO M. LÓPEZ GÓMEZ}

Iberni, L. G. (ed.) (1995b). Ruperto Chapi: memorias y escritos. Madrid: ICCMU.

Iberni, L. G. (2009). Ruperto Chapí. Madrid: ICCMU.

J. H. P. (1895). “Teatro del Tívoli: Corazón de fuego”. La Dinastía, 28-11-1895, p. 3.

J. H. P. (1897). “Teatro de Novedades: Nuestra Señora de París". La Dinastía, 19-04-1897, p. 1.

L. (1882). "Noticias, Teatro Real". La Unión, 16-01-1882, p. 3.

La Dinastía, 08-03-1887. "Un rapto, zarzuela en tres actos de los señores Colomer y Nicolau", p. 3.

La Dinastía, 10-09-1891. "Crónica”, p. 3.

La Dinastía, 03-11-1893. "Desde Olot”, p. 2.

La Época, 10-10-1896, “Noticias generales”, p. 3.

La Iberia, 10-05-1895. "Estreno de una ópera”, p. 2.

La Iberia, 14-05-1895. "La ópera de Albéniz: juicios de la prensa”, p. 2.

Larrad, M. (1991). "The lyric dramas of Enrique Granados (1867-1916)". Revista de Musicología, 14 (1-2), III Congreso Nacional de Musicología, "La música en la España del siglo XIX”, pp. 149-166.

Licenciado Caja, El [seud.] (1898). “María del Carmen”. Boletín Musical, 25-11-1898, p. 53.

Llorens, A. (2014) "Cuestión de dos: los hermanos Fernández Grajal en el Certamen Nacional de Ópera Española”, en M. Nagore y V. Sánchez (eds.), Allegro cum laude: estudios musicológicos en homenaje a Emilio Casares, pp. 195-200. Madrid: ICCMU.

López, F. M (2016). La ópera española en la escena madrileña (1868-1878) [Tesis doctoral], vol. I. Ciudad Real: Universidad de Castilla-La Mancha.

M. (1879). "Desde la butaca”. El Liberal, 09-10-1879, p. 3.

Malats, J. (1899). “María del Carmen”. La Música Ilustrada Hispano-americana, 10-06-1899, p. 5.

Mitjana, R. (s.f.). «Garín» en jPara música vamos!. Valencia: s.d.

Morphy, G. (1895). "Una ópera nueva en Barcelona”. La Correspondencia de España, 24-051895, p. 1. 


\section{CORRIENTES ESTÉTICAS EN TORNO A LA ÓPERA ESPAÑOLA (1868-1913)}

Muñoz, E. (1898). “María del Carmen, ópera española en tres actos, libro de Feliú y Codina, música del maestro D. Enrique Granados”. El Imparcial, 13-11-1898, p. 2.

Muñoz, E. (1902). “Circe”. El Imparcial, 08-05-1902, p. 2.

Obiols, M. (1874). "Gran Teatro del Liceo. L'ultimo abenzerraggio, drama lírico en cuatro actos del maestro Felipe Pedrell”. La España Musical, 18-04-1874, pp. 1-3.

Pedrell, F. (c. 1911). Jornadas de Arte (1841-1891). París: Librería Paul Ollendoreff.

Peña y Goñi, A. (1885). “Contra la ópera española (III)”. Madrid cómico, 01-03-1885, p. 7.

[Prensa no identificada], 06-01-1882. [Recortes de prensa relativos a la ópera Mitrídates], Archivo de la RABASF, Signatura 6-82-1.

Pujol Fernández, J. (1874). "L’ultimo abenzerraggio, drama en cuatro actos de D. F. Fors de Casamayor, música del maestro Felipe Pedrell’. La España Musical, 09-05-1874, pp. 34.

Rodríguez, G. A. (2006). "Joaquín Espín y Guillén (1812-1882): una vida en torno a la ópera española". Cuadernos de música iberoamericana, 12, pp. 63-88.

Sala, E. (1987). "In margine alla «première» della Vie Brève: Spagna e spagnolismi nella «couleur locale»", en P. Pinamonti (ed.), Manuel de Falla: tra la Spagna e l'Europa, Atti del Convegno Internazionale di Studi, pp. 121-129. Firenze: Leo S. Olschki.

Salvetti, G. (1987). "La Vida Breve: specchio deformante di naturalismo e folclore", en P. Pinamonti (ed.), Manuel de Falla: tra la Spagna e l'Europa, Atti del Convegno Internarionale di Studi, pp. 131-139. Firenze: Leo S. Olschki.

Sánchez, A. (1998). La Dolores. Algo más que una leyenda. Calatayud: Cometa.

Sánchez, V. (2002). Tomás Bretón: un músico de la Restauración. Madrid: ICCMU.

Sepúlveda, E. (1898). "Madrid teatral. Enrique Granados y su ópera María del Carmen". La Época, 08-11-1898, p. 2.

Serrano, E. (s.f.). Memorias autógrafas (capítulos referentes a sus años infantiles). Archivo de la RABASF, Signatura 6-82-1.

Serrano, E. Memorias [inéditas]. 


\section{FRANCISCO M. LÓPEZ GÓMEZ}

Sobrino, R (2002). “La ópera española entre 1850 y 1874: bases para una revisión crítica”, en E. Casares y A. Torrente (eds.). La ópera en España e hispanoamérica, vol. II, pp. 77142. Madrid: ICCMU.

Torres Clemente, E. (2007). Las óperas de Manuel de Falla: de La vida breve al Retablo de maese Pedro. Madrid: SEDEM.

Torres, J. (1998). “El huidizo grial de Isaac Albéniz” [Programa de concierto], en Ciclos Musicales Comunidad de Madrid: $6^{\circ}$ Concierto. Madrid, p. 8.

Weber, E. (2000). Manuel de Falla und die Idee der spanischen Nationaloper. Frankfurt: Peter Lang.

Zabala, A. (2004). "La producción liederística de Felip Pedrell”, Recerca Musicològica, 14-15, pp. 325-334.

Fecha de recepción: 24/05/2018

Fecha de aceptación: 10/09/2018 